\section{La salud de los migrantes y los servicios de salud en Medicina Familiar en Iberoamérica}

\section{The health of migrants and Family Medicine Health services in Iberoamerica}

\section{A saúde dos migrantes e os serviços de saúde de Medicina Familiar na Iberoamerica}

\begin{abstract}
Grupo de Trabajo:
Almeida Magda (Brasil); Borges Carina (Uruguay); Caballé María del Rosario (Argentina); Cabral Diana Ines (Argentina); Da Costa María Cristina (Venezuela), de Angulo Andrea (Colombia); Deza Castro Luis Alberto (Chile); Díaz Brito Ysabel María (República Dominicana); Fernández Maria (España); Fernández Ortega Miguel Ángel (México); Leyns B. Christine (Bolivia); Lezcano Portillo Federico (Paraguay); Luna Téllez Yossadara (México); Meyer Ana Lucía (República Dominicana); Meza Luna Elena Patricia (México); Montalvo Vázquez Johanna (Ecuador); Nadal Carmen (Chile); Ortiz Montalvo Armando (México); Perozo Juan Carlos (Venezuela); Polentinos Elena (España); Quintero Daymé (Panamá); Sánchez Núñez Flor Mariana (México); Suárez Cuba Miguel Ángel (Bolivia); Ulloa Jorge (Nicaragua); Zavala Cru Gad Gamed (México).
\end{abstract}

\section{Resumen}

Estudio exploratorio, transversal, descriptivo y cuali-cuantitativo, con el objetivo de determinar las condiciones de acceso y cobertura de los servicios de salud de Medicina Familiar y Atención Primaria para la población migrante en Iberoamérica. Se preparó un cuestionario con 22 preguntas relacionadas con el fenómeno de la migración y la prestación de servicios de salud en medicina familiar y atención primaria, el cual fue validado en apariencia y contenido por profesores de las Universidades de México, Colombia y Ecuador. Posteriormente fue respondida y documentada cada pregunta por los docentes e investigadores de 13 países de la región. Las conclusiones y recomendaciones propuestas por el Grupo de Trabajo sobre Migración y Salud de la VII Cumbre Iberoamericana de Medicina Familiar, fueron: a) reconocer el derecho a la salud de las personas migrantes y sus familias; b) incorporar en los programas de pregrado, posgrado y formación continua, las competencias necesarias para la atención integral de la población migrante y de sus familias y c) la creación de un observatorio de salud de los migrantes.

Palabras clave: Servicios de Salud; Salud; Migración; Medicina Familiar; Atención Primaria; Vulnerabilidad
Miguel Ángel Fernández Ortega ${ }^{a}$

Jacqueline Beatriz Roo Prato

Rocío Dávila Mendozac

Johanna Montalvo Vázquez ${ }^{\mathrm{d}}$

María Cristina Da Costa Dias ${ }^{e}$

Andrea De Angulo Losada

Alan Edward Barrellg

Daniel Abidán Alarcón Lerín ${ }^{h}$

a Facultad de Medicina, Universidad Nacional Autónoma de México (UNAM); Confederación Iberoamericana de Medicina Familiar (WONCA-Iberoamericana-CIMF). México. miguelaf03@live.com (Autor correspondiente)

${ }^{\mathrm{b}}$ Fondo de Pensiones del Sistema Banrural (FOPESIBAN). México. jroop3@gmail.com

c Facultad de Medicina, Universidad Nacional Autónoma de México (UNAM). México. rociodavilam@yahoo.com.mx

${ }^{d}$ Instituto de Salud de la Migración, Hospital UTPL; Confederación Iberoamericana de Medicina Familiar (WONCA-Iberoamericana-CIMF). Ecuador. johanna.montalvo@ hotmail.com

e Sociedad de Medicina Familiar de Venezuela (SOVEMEFA); Ambulatorio Militar "La Rosaleda". Venezuela. cristydacosta@yahoo.com

${ }^{\dagger}$ Sociedad Colombiana de Medicina Familiar (SOCMEF); Banco de la República de Colombia. Colombia. ayeyas@yahoo.es

${ }^{9}$ Facultad de Medicina, Universidad Autónoma de Guadalajara (UAG). México. aebarrell@yahoo.com

${ }^{\mathrm{h}}$ Instituto Mexicano del Seguro Social (IMSS), Clínica de Medicina Familiar No.10. México. 10.daniboy880109@hotmail.com

Financiación:

ninguna declarada.

Aprobación ética:

La investigación fue considerada una investigación sin riesgo. Los autores declaran que los procedimientos seguidos se realizaron de acuerdo a las normas éticas de la Asociación Médica Mundial y la Declaración de Helsinki.

Conflicto de intereses: ninguna declarada.

Procedencia y revisión por pares: revisado por pares.

Recibido el: 25/07/2018.

Aceptado el: 27/08/2018. 


\begin{abstract}
This is an exploratory, transverse, Qualitative-Quantitative descriptive research, whose objective is to determine the Primary Access and Family Medicine Healthcare conditions for the migrant population in Ibero-America. With the support of University Professors from the Mexico, Colombia and Ecuador Universities, a validated 22 question questionnaire was prepared with items related to the migration phenomenon and healthcare services in Primary Care access and Family Medicine. Subsequently it was responded by the involved researchers of the 13 countries in the region. The conclusions and proposed recommendations from the Work Group on Migration and Healthcare of the VII Iberoamerican Family Medicine Summit were: a) It is necessary to recognize the migrants and their family rights to proper healthcare b) Include in the undergraduate, postgraduate and continuous educational programs the needed capabilities and skills towards an integral healthcare of the migrant populations and their families and c) create a Migrant Health Observatory entity.
\end{abstract}

Keywords: Health Services; Healthcare; Health; Migration; Family Medicine; Primary Care; Vulnerability

\title{
Resumo
}

Estudo exploratório, transversal, descritivo e quali-quantitativo, com o objetivo de determinar as condições de acesso e cobertura dos serviços de saúde de Medicina de Família e Atenção Primária para a população migrante na América Latina. Foi elaborado um questionário com 22 perguntas relacionadas ao fenômeno da migração e da prestação de serviços de saúde em medicina de família e cuidados de saúde primários, que foi validado na forma e conteúdo por professores de universidades no México, Colômbia e Equador. Posteriormente, foi respondida e documentada cada pergunta por professores e pesquisadores de 13 países da região. As conclusões e recomendações propostas pelo Grupo de Trabalho sobre Migração e Saúde da VII Cúpula Ibero-Americana de Medicina de Família, foram: a) reconhecer o direito à saúde dos migrantes e suas famílias; b) incorporar em cursos de graduação, pós-graduação e educação continuada, as competências necessárias para o atendimento integral dos migrantes e suas famílias e c) a criação de um observatório da saúde dos migrantes.

Palavras-chave: Serviços de Saúde; Saúde; Migração; Medicina da Família; Atenção Primária; Vulnerabilidade

\section{Introducción}

El fenómeno de la migración ha tenido diferentes direcciones a lo largo de la historia del hombre. Durante la Colonia, el flujo de migrantes se llevó a cabo de forma masiva desde los países europeos hacia los americanos, africanos e incluso, Australia. Posteriormente, durante las Primera y Segunda Guerra Mundial, La Guerra Civil de España y muchos otros sucesos en el "Viejo Continente", continuaron propiciando que mucha de su población se instalara en América. ${ }^{1}$

En el Continente Americano, mucho del flujo migratorio mundial se ha dirigido a Estados Unidos de América (EUA) y Canadá, sobretodo, de países de habla inglesa, aunque cada vez hay más presencia de países asiáticos (China, India, Vietnam, etc.).

En el caso de México, país emisor del mayor número de emigrantes hacia EUA (13 millones aproximadamente); de tránsito de migrantes de Centro-Sudamérica y resto del orbe. También es uno de los principales receptores de inmigrantes iberoamericanos junto con España y EUA. ${ }^{1}$ Las remesas generadas por esta emigración, lo ubicó en 2014 como el tercer país a nivel mundial en recepción de remesas, sólo después de India y China. ${ }^{2}$

A pesar de que la migración global se ha incrementado de manera considerable en la última década, pasando de 150 a 214 millones, ${ }^{3}$ la migración intrarregional también ha crecido a un ritmo de $17 \%$ anual, no teniendo que ver necesariamente con la migración de Centroamérica y Caribe hacia los EUA. Tiene relación con la movilización de personas en otras subregiones de América Latina, que según datos de la Organización de Estados Americanos (OEA) y de la Organización para la Cooperación y Desarrollo Económico (OCDE), representa una cuarta parte de la migración total de la Región.4-6 
Según lo anterior, Argentina se constituye como el principal receptor de migrantes en el Cono Sur, con aproximadamente 1.5 millones de migrantes legalmente establecidos. ${ }^{4}$ Brasil, es un país muy estable, siendo la emigración más importante la interna hacia las grandes ciudades, no así en la inmigración, que reporta hasta el $17 \%$ procedente de Portugal. ${ }^{5,6}$

En la Región Andina de América del Sur, se puede observar como principal país expulsor de migrantes a Colombia, en gran medida a partir del conflicto armado con la guerrilla y grupos paramilitares. El otro país con gran movilidad es Venezuela, que debido al conflicto político, económico y social ha pasado de ser receptor de inmigrantes regionales a un país emisor de emigrantes. ${ }^{4-6}$

Históricamente, Ecuador ha sido un país expulsor de emigrantes, los principales destinos han sido EUA, España e Italia. En los últimos años se ha observado que la crisis económica mundial, el reconocimiento del país como de renta media y la creación de una nueva política migratoria, han incrementado el atractivo para muchos inmigrantes de los países vecinos. ${ }^{7}$

En Centroamérica y el Caribe los principales flujos migratorios son hacia EUA y Canadá, mientras que la emigración intrarregional está concentrada en dos países: Costa Rica y República Dominicana. En el primer caso, conformado principalmente por nicaragüenses, colombianos y estadounidenses jubilados. En el segundo, predominantemente haitianos. ${ }^{4-6}$

En 2007, España contaba aproximadamente 1.8 millones de personas extranjeras, predominantemente de Ecuador, Colombia y Argentina. ${ }^{1}$

Para fines de esta investigación se define migración humana como el movimiento de personas de un lugar a otro con la intención de establecerse permanentemente en el nuevo lugar. El movimiento es a menudo sobre largas distancias y de un país a otro, pero la migración interna es también posible. La migración puede ser de individuos, familias o de grandes grupos. ${ }^{8,9}$

\section{Objetivo}

Determinar la situación que guardan los servicios de salud de Medicina Familiar y Atención Primaria en Iberoamérica, en torno a la cobertura y acceso de la población migrante.

\section{Material y Métodos}

Estudio exploratorio, transversal, descriptivo y enfoque mixto: cuanti-cualitativo con fines de diagnóstico situacional, realizado entre los meses de septiembre de 2017 a enero de 2018. Se invitó a participar a uno o dos representantes expertos en el tema de los 20 países miembros de WONCA-Iberoamericana-CIMF. Los participantes eran docentes, investigadores o clínicos en ejercicio y se dieron a la tarea de investigar y documentar las respuestas a un cuestionario con 22 preguntas relacionadas con el fenómeno de la migración y la prestación de servicios de salud en medicina familiar y atención primaria en sus respectivos países. El instrumento exploraba seis dimensiones generales: flujos migratorios y económicos; perfil familiar y caracterización del migrante; vulnerabilidad del emigrante irregular; programas de protección y acceso a los servicios de salud; riesgos sanitarios en el proceso salud-enfermedad y formación de recursos humanos para la atención de migrantes. Dicho cuestionario fue elaborado, revisado y validado en su contenido y apariencia por profesores de diferentes instituciones educativas de México, Colombia 
y Ecuador. En un segundo momento la validación se hizo por los integrantes del grupo de trabajo en el estudio. El cuestionario fue enviado vía correo electrónico a cada uno de los investigadores participantes. La información proporcionada se concentró en un informe regional y posteriormente remitido nuevamente a los participantes del grupo para su revisión y aprobación. Posteriormente fue presentada para su análisis y discusión en la mesa de trabajo durante la VII Cumbre Iberoamericana de Medicina Familiar en Cali, Colombia en marzo de 2018.

\section{Resultados}

De los 20 países de la Región, sólo respondieron la encuesta 13 de ellos: Argentina, Bolivia, Brasil, Chile, Colombia, Ecuador, España, México, Nicaragua, Panamá, Paraguay, Uruguay y Venezuela. A continuación, se presentan los resultados obtenidos.

\section{La emigración en Iberoamérica (IBA)}

La emigración regional es muy variada y tiene características distintas en cada una de las subregiones de Iberoamérica. Aunque CIMF se constituye por cuatro subregiones (Mesoamérica, Andina, Cono Sur y Península lbérica), la presentación de los resultados puede o no coincidir con esta segmentación subregional.

En el Cono Sur, se observa que además de la afluencia de migrantes hacia Europa y EUA, también existe un flujo importante intrarregional. Argentina reportó para 2012, que los principales destinos de sus emigrantes fueron, España (30,2\%), EUA (23,3\%), Chile (8,5\%), Paraguay $(6,1 \%)$, Israel (5,0\%), Bolivia $(4,7 \%)$, Brasil $(2,9 \%)$ y Uruguay $(2,3 \%) .{ }^{10}$ Brasil también ha tenido una mayor emigración hacia Europa $(51,5 \%)$, con predominio hacia Portugal $(13,4 \%)$, España $(9,4 \%)$, Italia $(7,1 \%)$ y Reino Unido $(6,6 \%)$. El segundo lugar $(23,9 \%)$ hacia los EUA y en tercero hacia el continente asiático $(9 \%$, del cual, $7,4 \%$ va a Japón). ${ }^{11}$

En el caso de Paraguay la emigración es hacia los países contiguos, principalmente Argentina, que del año 2000 a 2010 tuvo un incremento de 70,5\% de inmigrantes paraguayos. Le sigue España y Brasil con casi 80 mil y 39 mil respectivamente en $2015 .{ }^{12}$

Para los chilenos, el país al que emigran mayormente es Argentina, seguida de EUA y posteriormente de otros destinos, como Suecia, Australia, Brasil, Venezuela, España, Francia y Alemania.

Uruguay reportó en orden de importancia los mismos destinos que Argentina y Brasil, tales como España, EUA y posteriormente Argentina y Brasil. ${ }^{13}$

En la Región Andina, integrada en este estudio por Bolivia, Colombia, Ecuador y Venezuela. Bolivia reportó que según el Censo Nacional de Población 2012, los principales sitios de acogida de bolivianos son: Argentina (38,2\%), España (23,8\%), Brasil $(13,2 \%)$, Chile $(5,9 \%)$, EUA $(4,2 \%)$, Italia $(1,8 \%)$ y Perú $(0,8 \%)$. Antes de la crisis económica de 2008 y de la exigencia de visa para los bolivianos a países de la Unión Europea (1 de abril 2007), España fue el principal destino. ${ }^{14,15}$ Bolivia tiene unos 10 millones de ciudadanos y aproximadamente 1,6 millones de emigrantes. En el censo 2012, 11,1\% por ciento de los hogares declaró tener algún familiar emigrante. ${ }^{16,17}$

Colombia es el país con mayor cantidad de emigrantes de Sudamérica (4,7 millones), lo que equivale a $10 \%$ de su población actual, seguido por Perú y Brasil. Según datos del Banco Mundial para 2011, los 
principales destinos de la emigración colombiana fueron EUA (28,8\%), Venezuela $(28,4 \%)$, España $(17,6 \%)$, Ecuador (8\%), Canadá $(2,1 \%)$ y posteriormente México, Panamá y Australia. ${ }^{18,19}$

Ecuador, se encuentra en el puesto $102^{\circ}$ de los 194 del ranking de emigrantes. Los 10 primeros países a donde migraron en 2015 fueron: Estados Unidos, España, Italia, Venezuela, Chile, Canadá, Colombia, Reino Unido, Alemania y Suiza. ${ }^{7}$

En el caso de Venezuela (2015), 606.344 venezolanos vivían en el exterior. No obstante, hay mucha emigración irregular, la cual es difícil dimensionar. En febrero de 2018, el informe de Tendencias Migratorias Nacionales en América del Sur, se observa que entre 2015 y 2017 la migración global de venezolanos se incrementó en 132\%, siendo los países escogidos: Colombia, EUA, España, Chile, Argentina, Italia, Ecuador, Panamá, Brasil, México, Perú y Portugal. Según datos consolidados de la Organización Internacional para las Migraciones (OIM), en 2015, el porcentaje de venezolanos fuera del país era de 2,3\% de su población y en 2017 se calcula en 4,7\% aproximadamente, lo que indica que casi un $80 \%$ de la emigración reciente desde Venezuela ha ocurrido principalmente durante los años 2016 y 2017. Al comparar las cifras de 2015 con las de 2017 se confirma una explosión en los movimientos de los venezolanos hacia otros países. ${ }^{20}$ (Cuadro 1)

Cuadro 1. Emigración en IBA: principales destinos según país, 2010-2017.

\begin{tabular}{|ll|}
\hline País de origen & Principales países de destino \\
\hline Argentina & España, EUA, Chile \\
Bolivia & Argentina, España, Brasil \\
Brasil & EUA, Portugal,Japón \\
Colombia & EUA, Venezuela, España \\
Chile & Argentina, EUA, España \\
Ecuador & EUA, España, Italia \\
España & Francia, Alemania, EUA \\
México & EUA, Canada, España \\
Nicaragua & Costa Rica, EUA, Guatemala \\
Panamá & EUA, Costa Rica, España \\
Paraguay & Argentina, España, Brasil \\
Uruguay & España, EUA, Argentina \\
Venezuela & Colombia, EUA, España \\
\hline
\end{tabular}

Fuente: Datos obtenidos de la investigación según referencias. ${ }^{10-25}$

En Mesoamérica, integrada en este estudio por México, Nicaragua y Panamá, se encontró que en el caso del primero, es el país con mayor flujo migratorio hacia los EUA, alcanzando en 2015, 97,81\% de su emigración total y alrededor de 13 millones de emigrantes; Canadá en segundo lugar 0,61\%; España $0,41 \%$; Alemania en cuarto lugar, $0,15 \%$ y Guatemala $0,15 \% .^{22}$

Nicaragua reporta que $14.0 \%$ de su población vive en el extranjero, principalmente en Costa Rica y EUA, aunque le siguen Guatemala, El Salvador y en menor grado España y Honduras, representando aproximadamente tres cuartas partes de la migración intrarregional en Centroamérica. ${ }^{23}$

En Panamá, 52\% de emigrantes van a EUA; 6,4\% Costa Rica; España 6,2\%; Colombia 3,8\% y China Continental recibe $2,8 \%$ de los panameños. ${ }^{24}$ 
España es uno de los principales países receptores de migrantes latinoamericanos. Posterior a la crisis económica que inició en 2008, muchos españoles se quedaron sin trabajo o vieron frustradas sus expectativas de vida, por lo que decidieron migrar a otros países. En 2009 había 1.000.047 mil residentes españoles en el extranjero, según el Instituto Nacional de Estadística de ese país, la cifra de migrantes españoles se incrementó durante los ocho años siguientes, llegando en 2017 a 2,40 millones de personas, de las cuáles, 794.209 (33\%), son nacidas en España, el restante 67\%, son extranjeros nacionalizados, superando la cifra de 1,6 millones de personas. Su destino favorito para emigrar fue la Unión Europea (425.919, en 2017). En 2009, 819.731 nacionalizados españoles regresaron a su país de origen, calculando que de ellos, 578.763 (71\%), lo hicieron a América Latina. Ocho años después, la cifra de nacionalizados que han vuelto a su país se ha duplicado (de 755.923 a 1.000 .042 de personas). Los principales países receptores de migrantes españoles son Francia, Alemania, Reino Unido, Argentina y Venezuela. Los dos últimos hacen referencia a los españoles nacionalizados que regresaron a su país de origen. ${ }^{25}$

\section{La inmigración en países de IBA}

Según el último Censo 2010, en Argentina vivían 1,805.957 personas de nacionalidad extranjera, que representaban $4,5 \%$ de la población total. De ellas, 3,67\% proceden del Continente Americano. Es el principal país receptor de la migración intrarregional, teniendo mayor relevancia Paraguay $(36,4 \%)$, Bolivia $(23,5 \%)$, Chile (13\%), Perú (10,6\%), Uruguay $(7,9 \%)$ y Brasil $(2,8 \%) .{ }^{10}$ Dicha migración ha sido favorecida por los acuerdos de integración regional (el Mercado Común del Sur [MERCOSUR] y la Comunidad Andina de Naciones) que facilitan la movilidad intrarregional. Por otro lado, también se observa crecimiento en el número de migrantes no sudamericanos quienes tienen mayor vulnerabilidad que los migrantes regionales por el difícil acceso a la regularidad migratoria. ${ }^{20}$ En los últimos años se observó un incremento de inmigrantes dominicanos y venezolanos, llegando estos últimos a tener un incremento porcentual de 903\% (1,936 en 2017). Otros flujos de inmigrantes de importancia son los afectados por el conflicto de la República Árabe de Siria, que de octubre de 2014 a octubre de 2017, ha recibido 828 solicitudes de ingreso. Así mismo, se concedió 4,747 residencias a ciudadanos de Senegal entre 2010 y 2015 (97,7\% Hombres y 2,3\% Mujeres). ${ }^{26}$

En Chile, según datos de la Organización de Naciones Unidas (ONU), en 2010 los inmigrantes eran 369,436 , cifra que se incrementó a 469,436 en 2015, un alza de $27 \%$, lo que corresponde a $2,7 \%$ de la población total. Entre 2005 y 2016, en Chile se otorgaron 323,325 Permanencias Definitivas, siendo la comunidad peruana la más beneficiada, con 123,401 (38\%); posteriormente la boliviana (13,5\%), y la colombiana (13\%). . $^{27-29}$

La inmigración en Uruguay pareciera ser menos intensa y diversa, los datos reportados corresponden a personas provenientes de Argentina y Brasil principalmente. De los inmigrantes europeos el principal emisor es España. ${ }^{13}$

De acuerdo con el Censo de 2010, Brasil posee 0,3\% de la población compuesta por extranjeros, lo que totaliza poco menos de $600,000^{30}$ habitantes provenientes de Portugal (21\%), Haití (8\%), Bolivia (8\%), Japón (7\%), Italia (6\%), España (5\%), Argentina (5\%), China (5\%) y EUA (3\%).

Bajo la condición de refugiados, hasta 2015 recibieron 10,308 solicitudes, siendo en su mayoría de personas de Venezuela (33\%), Cuba (13\%) y Angola (13\%). En 2016 se registraron 9,552 refugiados, de 82 
nacionalidades, ${ }^{31}$ según lo reportado por la ONU, los países de procedencia fueron: Siria (27\%), Colombia (13\%), República Democrática del Congo (13\%), Angola (12\%), y Palestina (5\%). En el mismo año se recibieron 35.351 solicitudes de asilo de personas originarias de Haití (20\%), Senegal (15\%), Venezuela (12\%), Angola (7\%), Nigeria (7\%), Cuba (6\%), Siria (3\%) entre otros (Cuadro 2).

Cuadro 2. Inmigración en IBA: principales países de origen, 2010-2017.

\begin{tabular}{|ll|}
\hline País receptor & Principales países de origen \\
\hline Argentina & Paraguay, Bolivia, Chile \\
Bolivia & Argentina, Brasil, España \\
Brasil & Portugal, Haití, Bolivia \\
Colombia & Venezuela, Ecuador, EUA \\
Chile & Peru, Bolivia, Colombia \\
Ecuador & Colombia, Perú, EUA \\
España & Marruecos, Rumania, Ecuador \\
México & EUA, Gautemala, España \\
Nicaragua & Honduras, El Salvador, Mexico \\
Panamá & Colombia, Venezuela, Nicaragua \\
Paraguay & Brasil, Argentina, España \\
Uruguay & Argentina, Brasil, España \\
Venezuela & Colombia, España, Portugal \\
\hline
\end{tabular}

Fuente: Datos obtenidos de la investigación según referencias. ${ }^{7,10,13,14,20,26-38}$

En cuanto a la Subregión Andina, para el año 2015 vivían en Venezuela 1,404,448 inmigrantes, representando $4,5 \%$ de la población total del país, ${ }^{20}$ teniendo como principales países de origen Colombia, Cuba, Bolivia y Haití. Durante muchos años Venezuela fue un país receptor de inmigrantes, tal y como lo refleja el alto porcentaje de esta población, no obstante, en los últimos años se ha tornado en un país emisor de migrantes.

Bolivia en 2012, reportaba 119,033 personas nacidas en el exterior, representando $1,2 \%$ de la población total, de los cuales $52,3 \%$ son hombres y $47,7 \%$ mujeres. Los países de procedencia fueron Argentina $(30,4 \%)$, Brasil $(18,5 \%)$, España $(8,6 \%)$, Perú $(7,8 \%)$ y México $(7,1 \%)$. De esta inmigración internacional 44,0\% reside en Santa Cruz; Cochabamba tiene 17,6\% y La Paz alberga 14,4\%. De ellos, ocho de cada 10 viven en el área urbana; 23,4\% declaró haber llegado al país entre los años 2010 y 2012. Al comparar los datos de 2012 con los de 2001, se observa un incremento en el número de inmigrantes menores de 14 años con $4 \%$ y una disminución de 3,9\% en el grupo de 15-64 años. ${ }^{14,32}$

En cuanto a la situación de inmigrantes en Colombia, los datos señalan un total de 109,971 personas procedentes de otros países, los más importantes son Venezuela, Ecuador, EUA y España, lo que corresponde a $0,27 \%$ de la población total (DANE, 2005). La participación porcentual por continentes de procedencia es: América del Sur (43,3\%), América del Norte (31,2\%), América Central y el Caribe (13,8\%), Europa (11,0\%), Asia, Oceanía y África son los continentes con menor procedencia de extranjeros. ${ }^{33}$

En Ecuador, de 2001 a 2010 ingresaron alrededor de 200,000 personas, estimándose que la tasa de inmigración en el 2010 fue de 1.2\%, incrementado 0,3\% en relación con 2001. Los países de procedencia en orden de importancia para ese año fueron Colombia, Perú, EUA, España, Cuba y Venezuela. ${ }^{34}$ 
En México se reporta como principal grupo de inmigrantes a personas provenientes de EUA (69.7\%), Guatemala (4.9\%), España (4.3\%), Colombia (1.3\%), Argentina (1.3\%), otros grupos de inmigrantes son más pequeños. En conjunto todos representaban 1\% de la población total, según el último Censo de 2010, que detectó 961,000 personas extranjeras. ${ }^{35}$

Nicaragua en 2010 estimó que 40,000 extranjeros vivían en su territorio, según datos del Banco Mundial, destacando la inmigración intrarregional de centroamericanos, especialmente de Honduras y El Salvador, los cuales son favorecidos por los acuerdo de libre movilidad (CA-4). ${ }^{36}$ El Convenio Centroamericano de libre movilidad o CA-4 es un acuerdo firmado en junio de 2006 por cuatro de los países de América Central (Guatemala, EI Salvador, Honduras y Nicaragua), estableciendo la libre movilidad entre los ciudadanos de los países firmantes sin restricciones adicionales más que sus documentos de identidad nacional. Sin embargo, a los menores de edad se les exige pasaporte para evitar el tráfico ilegal de niños. ${ }^{37}$ De la población inmigrante residente en el país, los hondureños conforman el grupo más amplio, agrupan $36,3 \%$, siguiendo los mexicanos, cubanos, españoles, rusos, alemanes y colombianos. Los de origen africano representaron $4,16 \%$ de la población extranjera y los asiáticos 1,2\%. Según datos de la Policía Nacional, se calcula que sólo se registran del 5 al 10\% de las personas que llegan o transitan por el país, lo que estiman pudiera traducirse en al menos 60,550 a 121,100 inmigrantes irregulares en el periodo de 1990 a 2005, los cuales provienen principalmente de Perú, Ecuador, Colombia, India, Republica Dominicana, Costa Rica y China Continental. La proporción de migrantes extra regionales pasó de ser 18,0\% de los inmigrantes en 2006 al 60,0\% en 2009, siendo los principales países de origen Eritrea, Somalia y Etiopia. ${ }^{38}$

En la inmigración que se tiene registrada en Panamá (2010), se encontró que el principal grupo corresponde a colombianos $(28,2 \%)$, seguido por venezolanos $(17,1 \%)$, nicaragüenses $(9,1 \%)$, chinos $(5,9 \%)$ y dominicanos $(5,4 \%) .{ }^{24}$

En España, los principales países de procedencia son Marruecos $(11,96 \%)$, Rumanía $(11,25 \%)$ y Ecuador (7,21\%). En los últimos años, el número de inmigrantes que viven en España, ha disminuido en 427,112 personas $(6,8 \%)^{7}$

\section{La importancia de las remesas en los países de la Región}

Las remesas generadas por los emigrantes son muy importantes para la economía de los países de Iberoamérica (no sólo de América Latina). En este sentido, vemos que de los veinte primeros países receptores de remesas del ranking mundial en 2016, hay dos de la región, México en cuarto lugar con $28,143$ millones de dólares (4,8\% del total mundial), que equivale a 2,3 \% del Producto Interno Bruto (PIB $)^{22}$ y España en treceavo con 10,080 (1,7\%). Las remesas se han ido incrementando progresivamente en los últimos años y se espera que sigan así. Los principalmente países de procedencia del flujo económico son Francia, Alemania y EUA. ${ }^{7,22,39}$

Nicaragua es otro país cuya importancia de las remesas es fundamental, así se muestra cuando observamos que en el primer trimestre de 2017, los ingresos por remesas correspondieron a 9,6\% del PIB, con ingresos procedentes de la economía estadounidense $(56,0 \%)$, Costa Rica $(20,2 \%)$, España $(9,6 \%)$, Panamá $(5,9 \%)$, El Salvador (1,0\%), Canadá y México (0,9\% y 0,3\% respectivamente). ${ }^{40}$ No obstante que la dependencia económica de las remesas para Nicaragua es evidente, en países como Panamá no tiene 
la misma trascendencia, en 2016 se recibieron un total de 505,7 millones de dólares; principalmente de EUA, Costa Rica y España, lo que representó 0,92\% del PIB. ${ }^{7}$

En el Cono Sur, el flujo económico por remesas parece no ser tan importante, así vemos que en el caso de Paraguay (2016), ingresaron remesas por valor de 656.9 millones de dólares, 103.3 millones de dólares más que en 2015. Los flujos de dinero proceden principalmente de tres países: Argentina, España y Brasil. ${ }^{7}$ Así mismo, en Uruguay, $2.4 \%$ de los hogares recibió remesas en el año encuestado con un monto mensual promedio de 150 dólares, 60\% destinado para Montevideo. ${ }^{13}$ En el caso de Brasil, se recibieron remesas mensuales con una media de US \$ 200 millones de dólares (2,400 millones al año).

Tanto en Argentina como en Chile, los ingresos por remesas tienen un bajo impacto económico. En el caso de la primera, en 2016, se recibieron 349 millones de dólares, lo que equivale a 0,4 \% del PIB. ${ }^{41}$ Al parecer los emigrantes argentinos, no envían dinero de manera regular a sus familias. En el mismo sentido, los ingresos por remesas en Chile no son considerados importantes y provienen de países como Argentina, EUA y España principalmente. ${ }^{7}$

En Colombia, las remesas enviadas según informes del Banco de la República, representan entre el 1,7 a $1,8 \%$ del PIB, siendo el Valle del Cauca el departamento que más remesas recibe (33\%), alcanzando hasta 3\% del PIB para los Vallecaucanos. ${ }^{7,33}$ Bolivia en 2016, recibió remesas por valor de 1.217,2 millones de dólares procedentes de Argentina, España y Estados Unidos (18,4 millones de dólares más que en 2015), lo que equivale $3,60 \%$ del PIB. ${ }^{7}$ Aunque, también se refiere un decremento importante en los últimos años por causas atribuibles a la crisis internacional. ${ }^{42}$

Ecuador cuenta con dos fuentes de financiamiento: el petróleo y las remesas. ${ }^{43}$ Las segundas constituyen la segunda fuente de ingresos del país, representando en $20087,4 \%$ del PIB, posteriormente se ha observado un descenso, que a partir de 2011 a oscilado en alrededor del 3,5\% de este Producto. ${ }^{34}$ En 2016 las remesas provinieron principalmente de EUA, España e Italia. El resto llegó de Reino Unido, México, Chile, Perú, Canadá, Alemania, Suiza, Bélgica, Francia y Colombia. ${ }^{44}$

Venezuela es un país difícil de analizar, ya que sus cifras no son confiables. Según datos oficiales, las remesas enviadas a Venezuela por los emigrantes, para el año 2016, representaron $0,0 \%$ del PIB, incluso, con crecimiento negativo $(-6,3 \%) .{ }^{41}$ No obstante que estos datos no son creíbles, ya que hoy más que nunca la emigración de venezolanos hacia muchos otros países implica que el flujo de remesas es mayor. Las dificultades planteadas por el gobierno venezolano en el control cambiario, obliga a los ciudadanos a utilizar mecanismos informales para el ingreso de divisas, según lo observado entre la población. En este sentido, una empresa encuestadora privada registró que $88 \%$ de las familias de emigrantes afirman recibir dinero desde el exterior.

\section{Principales motivos de emigración en IBA}

Los principales motivos por los que las personas emigran en Iberoamérica son seis: a) cuestiones económicas y laborales, b) reunión familiar, c) cuestiones políticas d) conflictos bélicos, e) estudios y f) factores ambientales.

En relación a las cuestiones económicas y laborales vemos que también están en relación directa con los reencuentros familiares. Prácticamente todos los países tienen estas causas de migración, estimulada por 
la pobreza y la falta de empleo o por una mejor remuneración, como ocurre en los 13 países encuestados. En este punto es importante distinguir entre la migración regular o legal y la irregular o también conocida como ilegal. En IBA se da con gran frecuencia la migración irregular, que marcadamente es intrarregional, tal como ocurre entre EUA, México, y los países de Centroamérica. Para muchos de estos migrantes los trámites de visado son procesos muy engorrosos, caros y difíciles de conseguir. Lo mismo ocurre entre los países de la subregión Andina y del Cono Sur, con un alto porcentaje de inmigrantes intrarregionales entre Colombia, Venezuela, Ecuador, Bolivia, Perú, Brasil, Chile, Argentina, Uruguay y Paraguay. No obstante, esta condición de migración irregular frecuente, conlleva mayores riesgos a su salud, dado, que tratan de evadir los filtros migratorios, la delincuencia e incluso exponen su vida. . $^{10,13,19,20,22,33-35,45-50}$

En Ecuador al igual que en Bolivia y Paraguay, se ha presentado el fenómeno de feminización de la migración ya que se ha considerado que las principales causas de emigración son la crisis económica, disminución de la tasa de empleo, y reunión familiar, además de que las mujeres se insertan al mercado laboral de manera más sencilla. ${ }^{34}$

Por otro lado, también tenemos la migración regular o legal, que bajo los mismos motivantes económicos viajan con mayor seguridad y planeación, buscando con frecuencia establecerse en el lugar receptor. Estas personas suelen tener mejores niveles de estudios, lo que les permite conseguir un mejor empleo con mejores ingresos. Esto también ocurre en los 13 países, encuestados, siendo notable la situación de España, décimo país receptor de inmigrantes a nivel mundial, pero que también es un importante emisor de emigrantes jóvenes ( 25 a 35 años), con estudios universitarios e idiomas, que debido en parte a la crisis económica que persiste, buscan mejores oportunidades de empleo, principalmente en otros países de Europa. ${ }^{51,52}$

Las cuestiones políticas y conflictos armados, han sido detonantes de migración a gran escala, como ocurrió en Nicaragua, entre 1970 y 1980 por la Revolución Sandinista y la Contrarrevolución en tiempos de la Guerra Fría, o el conflicto bélico en Colombia producido por las Fuerzas Armadas Revolucionarias (FARC- EP), La Dictadura de Pinochet en Chile y más recientemente los conflictos políticos en Argentina, Bolivia, Paraguay y la "Migración de Escape" de Venezuela, que en este último caso se debe al colapso económico y político. ${ }^{19,38,49,53,54}$

Otra causa de Migración reportada fue la de estudios en el extranjero, principalmente en Chile y Colombia, ya que en este último país es muy costosa la educación posgraduada. 33,45,49

Los factores ambientales fueron reportados por Bolivia y Nicaragua. El primero haciendo referencia a las sequías, inundaciones y, derrumbes por reblandecimiento de la tierra. El segundo, hace referencia a fenómenos meteorológicos como el Huracán Mitch (1998), que incrementó en 40\% la emigración hacia Costa Rica. ${ }^{36,47}$

\section{Principales áreas de trabajo de los inmigrantes en los países receptores}

En general, todos los países reportan que las actividades en las que se desempeñan los trabajadores inmigrantes tienen relación con los tres sectores de la producción, predominando la agricultura, la ganadería, la construcción, trabajadoras del hogar, servicios, comercio, la matanza y procesamiento de carnes, la industria textil, etc. Brasil, al igual que Chile, Colombia, Bolivia, Argentina, Ecuador, España y 
México, refieren que un alto porcentaje de su población migrante tiene estudios avanzados o universitarios, dedicados a actividades de carácter científico y/o académico, así como de negocios. En algunos casos, como en España, es frecuente encontrar un amplio contingente de trabajadores que ocupan posiciones en la estructura laboral muy por debajo del nivel real de sus cualificaciones, ocurriendo más frecuentemente con los trabajadores informales. ${ }^{10,19,22,42,55-62}$

\section{¿Los emigrantes viajan solos o con familia en la Región?}

No existen datos confiables al respecto, no obstante, varios de los países proporcionaron información que permite hacer algunas inferencias, por ejemplo: Nicaragua reporta que la mayoría de los emigrantes a Costa Rica viajan solos, con la intención de reagruparse posteriormente con la familia. La información revela que un importante porcentaje de hogares costarricenses son de composición binacional, encontrando que $36,8 \%$ de los nacidos en Costa Rica viven en hogares con un jefe de familia nicaragüense y en menor medida cónyuges y otros familiares. De estos hogares binacionales, el 36,9\% del total de jefes de familia eran nacidos en Costa Rica, y 62,6\% en Nicaragua. ${ }^{63,64}$ Otro dato importante, es el proporcionado por Paraguay, refiriendo que las personas que emigran en su mayoría viajan en principio solas y con el trascurso de los años llevan a sus familiares; son personas jóvenes en edad productiva, y especialmente mujeres. La Encuesta Permanente de Hogares (EPH), en 2012, muestra que cerca de $60 \%$ de los emigrados registrados son mujeres: $52 \%$ en Argentina y $80 \%$ en España. En cuanto a las edades, la mayoría se encuentra en el rango de 20 a 34 años (34\%, entre 20 y 24 años, $18 \%$ entre 25 y 29 años). ${ }^{65}$

En Bolivia, se refieren patrones de emigración más o menos comunes entre la población, como es el hecho que cuando se quieren mejorar los ingresos "solo un miembro de la familia sale", mientras que cuando se busca un empleo "es casi normal ver que toda la familia se va del país en busca de nuevos destinos". ${ }^{66,67}$ Entre 2004 y 2007 se observó un flujo predominantemente femenino (64\%), que al parecer fue motivado por la mayor facilidad para conseguir trabajo. De las mujeres-madres que migraron desde Cochabamba, 91\% lo hizo bajo el patrón independiente y tan sólo el $9 \%$ bajo el patrón asociativo de reunificación familiar. De acuerdo a los familiares de estas mujeres, las razones que motivaron la migración fueron: la desocupación $(55 \%)$, otras (31\%), reunificación familiar $(9 \%)$ y $4 \%$ maltrato intrafamiliar. ${ }^{66}$ Los emigrantes bolivianos en España tuvieron mayores tasas de irregularidad que otros de la región, lo que obviamente los hace más vulnerables en términos laborales y jurídicos y con mayor dificultad para reagrupar a su familia, resultando también más propensos a tener que retornar. ${ }^{68}$

En Colombia, según se refiere, los emigrantes que buscan mejores oportunidades laborales suelen viajar solos en un inicio y reunir al resto de la familia en el país receptor. ${ }^{45}$ Igual situación ocurre con los venezolanos, la mayoría son emigrantes jóvenes, solteros, que viajan solos, de hecho, según algunas investigaciones no oficiales, Venezuela es el segundo país que presenta mayor porcentaje de niñas y niños viviendo en el exterior. ${ }^{69}$

El caso de Argentina, en la emigración hacia España, reporta una situación un tanto diferente, según reportes oficiales, $53,2 \%$ de los hombres llegaron a ese país solos, sin pareja ni hijos, mientras que $46,3 \%$ lo hizo con pareja y/o hijos. Las mujeres viajaron $44,1 \%$ sin pareja ni hijos y $18,9 \%$ con pareja y/o hijos. ${ }^{70}$ 
En Ecuador los emigrantes viajan solos con la esperanza de reunir a su familia en el futuro inmediato, esta reflexión se corrobora con las declaraciones de la Viceministra de Movilidad Humana quien en 2014 indicó: "Este año tenemos una terrible y lamentable cifra que supera los 600 niños que han viajado no acompañados en busca de sus familias", el triple de los casos registrados en $2013 .{ }^{71}$

Finalmente, en España se refiere que el emigrante suele ser varón, joven de 30-34 años, principalmente de Cataluña, Comunidad de Madrid y Comunidad valenciana y en algunas ocasiones podemos hablar de jóvenes parejas con hijos. ${ }^{72}$

\section{Las agresiones y/o abusos a inmigrantes}

La persona migrante es muy vulnerable desde el mismo instante en que decide marcharse de su hogar y emprender la búsqueda de un mejor futuro. Requiere el valor y la decisión de desprenderse de la familia, las costumbres, la seguridad, del alimento. Enfrentar los retos del tránsito migratorio hasta el destino soñado, y finalmente, tratar de insertarse en la sociedad meta, para asimilarse y alcanzar el objetivo de una mejor calidad de vida.

El proceso migratorio no es sencillo, el inmigrante está expuesto a diferentes riesgos a su salud, tanto por enfermedades comunes, como por accidentes, agresiones y/o abusos de que son objeto. En este sentido, vemos que las actitudes de rechazo hacia los inmigrantes son variadas de país a país, por ejemplo, en Uruguay, Bolivia y Argentina, las personas presentan actitudes agresivo-pasivas, como la indiferencia, marginación, exclusión social, e intolerancia, dificultando los vínculos interculturales y produciendo cambios y conductas reactivas entre las recién llegados. ${ }^{73-76}$ En el caso de Chile, las actitudes racistas pueden observarse en lo cotidiano con ejemplos claros como el arrendamiento de habitaciones a precios abusivos, además en condiciones indignas de hacinamiento y falta de higiene; diversas agresiones físicas, en particular a personas de raza negra. ${ }^{77}$

Otros países tienen un componente de violencia sexual más importante, como ocurre en Colombia, Nicaragua e incluso Paraguay, que en el caso del primero, se ha destacado por ser país de origen, tránsito y destino para la trata de personas, con delitos como la explotación sexual, los trabajos forzados y el narcotráfico. En el caso del segundo, el Fondo de las Naciones Unidas para la Infancia (UNICEF), estima que hay alrededor de 4.800 niños, niñas y adolescentes que son sexualmente explotados comercialmente en Managua. Esto es un indicador del alto número de trata de personas. ${ }^{78,79}$

Venezuela al parecer no tiene problemas de abuso hacia los migrantes, el único hecho aparentemente violatorio de sus derechos humanos ocurrió en 2015, a través de la deportación injustificada de ciudadanos colombianos ordenada por el Estado. En este contexto, se hizo mención del aparente incumplimiento del procedimiento administrativo de deportación y de la eventual violación de los derechos de algunas de las personas deportadas. ${ }^{80}$

Se considera que Ecuador tiene un notable aumento inmigratorio especialmente de indocumentados desde hace 4 años, este fenómeno ha causado cambios en la sociedad y se observan reportajes en los periódicos de casos de xenofobia y explotación laboral.

Según los reportes proporcionados, México y España son los países más violentos para los inmigrantes, aunque, bajo diferentes circunstancias. En el caso de España, se hace referencia a una mayor variedad de agresiones xenofóbicas y racistas. Según el reporte RAXEN 2016, se constatan 500 incidentes 
comprobados o documentados, frente a los 452 que recogieron en el informe de 2015, cuando se tuvo pruebas de 284 agresiones y 136 incitaciones al odio. De enero a diciembre de 2016 esta organización recogió datos inquietantes al registrar en la Comunidad de Valencia (93 incidencias), Madrid (72), Cataluña (58), Andalucía (57), Castilla-León (31), Aragón (27), y Baleares, Murcia, Euskadi, Navarra (con más de 20), detectándose incidentes en todas las Comunidades Autónomas. ${ }^{81,82}$ Respecto a las agresiones sexuales, un tercio de las mujeres víctimas son inmigrantes, siendo sus agresores $75 \%$ españoles y $25 \%$ no habían nacido en España. ${ }^{83}$ Reportes de Médicos del Mundo, muestran que el $85 \%$ de los pacientes que atendieron han experimentado violencia antes, durante o después de su migración, y un tercio de los solicitantes de asilo han sido torturados. ${ }^{84}$ Además se encuentran en situación especialmente delicada a las mujeres inmigrantes y refugiadas, así como los menores en tránsito por sufrir un alto porcentaje de violencia económica, psicológica, física y sexual (Cuadro 3).

Por su parte, México parece el país más violento en relación a la delincuencia organizada, no por xenofobia hacia los migrantes. Ocurre principalmente con los que se encuentran en tránsito y más aún, en la cercanía a las fronteras con Estados Unidos y Guatemala. Los emigrantes mexicanos y de todas las nacionalidades que tratan de pasar la frontera de forma ilegal reciben maltrato en la frontera con EUA $65-85 \%$ de las veces, las principales agresiones son: la violencia física con robo, especialmente de dinero e identificaciones y la violencia física, verbal y psicológica, extorsión, secuestro y violaciones sexuales, que aunque también están presentes, el porcentaje de incidencia es menor respecto de las otras. ${ }^{85-87}$

\section{Programas formales de atención a los migrantes en los países de IBA}

Al respecto de la presencia de legislación y programas formales de atención en salud para población migrante vemos que sólo tres países cuentan con ellos, Argentina, Ecuador y México. En el caso de Argentina, existe el Programa de Apoyo para Integración Social del Migrante (PAIS Migrante). Se propone la constitución de un "Centro de Orientación a Migrantes y Refugiados", que permite brindar información válida, como la realización de trámites migratorios, asesoramiento y acompañamiento jurídico, prevención de la violencia de género, violencia institucional, y toma de denuncias en caso de actos de discriminación, y sobre todo, talleres de empoderamiento, clases de idiomas, introducción al empleo y talleres de oficios. Además de proporcional un lugar para aquellas personas que no tengan sede para reunirse. ${ }^{88}$

En Ecuador, en marzo del 2007, se creó la Secretaría Nacional del Migrante - SENAMI siendo la encargada de definir y ejecutar las políticas migratorias, encaminadas al desarrollo humano de todos sus actores, sirviendo de enlace en todas las acciones de atención, protección y desarrollo del migrante, según la política del Estado Ecuatoriano;89 aquí se contemplan programas como "Ecuador Saludable vuelvo por ti" y "Retorno de Personas con Enfermedades Catastróficas" otorgado por el Ministerio de Salud Pública, así como "Retorno de Personas con Discapacidades" otorgado por la Vicepresidencia de la República del Ecuador. Actualmente todos los programas de asistencia a los migrantes los lleva el Ministerio de Relaciones Exteriores y Movilidad Humana. ${ }^{90}$

En el caso de México, cuenta con instituciones gubernamentales cuyo objetivo es trabajar en beneficio de esta población vulnerable, tales como el Instituto de Mexicanos en el Exterior (IME), El Instituto Nacional de Migración (INM), entre otros, contando con diversos programas al respecto, los más importantes son: 
Cuadro 3. Vulnerabilidad y Acceso a los Servicios de Salud.

\begin{tabular}{|c|c|c|c|c|c|c|}
\hline PAÍS & $\begin{array}{l}\text { Agresiones y Abusos } \\
\text { a migrantes }\end{array}$ & Migración infantil & $\begin{array}{l}\text { Albergues para } \\
\text { migrantes }\end{array}$ & $\begin{array}{l}\text { Programas } \\
\text { formales de } \\
\text { atención a } \\
\text { migrantes }\end{array}$ & $\begin{array}{l}\text { Acceso a los } \\
\text { Servicios de } \\
\text { Salud }\end{array}$ & $\begin{array}{l}\text { Medicamentos } \\
\text { gratis para } \\
\text { migrantes }\end{array}$ \\
\hline Argentina & $\begin{array}{l}\text { Actitudes } \\
\text { agresivo-pasivas }\end{array}$ & $\begin{array}{l}\text { Inmigración } \\
\text { diversa }\end{array}$ & No & Sí & Gratuito & Sí \\
\hline Bolivia & $\begin{array}{l}\text { Actitudes } \\
\text { agresivo-pasivas }\end{array}$ & $\begin{array}{l}\text { Inmigración de } \\
\text { Brasil, Colombia, } \\
\text { Ecuador y Perú }\end{array}$ & $\begin{array}{l}\text { Sí, religiosos y } \\
\text { civiles }\end{array}$ & No & $\begin{array}{l}\text { En algunos } \\
\text { programas } \\
\text { específicos }\end{array}$ & $\begin{array}{l}\text { No, sólo a } \\
\text { migrantes } \\
\text { regulares }\end{array}$ \\
\hline Brasil & No & Sin datos & No & No & Gratuito & Sí \\
\hline Colombia & $\begin{array}{l}\text { Violencia sexual y } \\
\text { trata de blancas }\end{array}$ & Sin datos & $\begin{array}{l}\text { Sí, religiosos y } \\
\text { civiles }\end{array}$ & No & $\begin{array}{l}\text { En emergencia } \\
\text { médica o } \\
\text { quirúrgica }\end{array}$ & No \\
\hline Chile & $\begin{array}{l}\text { Actitudes racistas y } \\
\text { xenofóbicas }\end{array}$ & $\begin{array}{l}\text { Inmigración } \\
\text { diversa }\end{array}$ & $\begin{array}{l}\text { Si, del Estado, } \\
\text { religiosos y civiles }\end{array}$ & No & $\begin{array}{l}\text { En emergencia } \\
\text { médica o } \\
\text { quirúrgica }\end{array}$ & $\begin{array}{l}\text { Sí, en } \\
\text { instituciones } \\
\text { específicas }\end{array}$ \\
\hline Ecuador & $\begin{array}{l}\text { Xenofobia y } \\
\text { explotación laboral }\end{array}$ & $\begin{array}{l}\text { Inmigración de } \\
\text { Colombia y Perú }\end{array}$ & $\begin{array}{l}\text { Si, del Estado, } \\
\text { religiosos y civiles }\end{array}$ & Sí & Gratuito & Sí \\
\hline España & $\begin{array}{l}\text { Agresiones } \\
\text { xenofóbicas y racistas } \\
\text { muy intensas }\end{array}$ & $\begin{array}{l}\text { Inmigración } \\
\text { diversa }\end{array}$ & $\begin{array}{l}\text { Si, del Estado, } \\
\text { religiosos y civiles }\end{array}$ & No & $\begin{array}{l}\text { En emergencia } \\
\text { médica o } \\
\text { quirúrgica. Varía } \\
\text { en algunas } \\
\text { Comunidades } \\
\text { Autónomas }\end{array}$ & $\begin{array}{l}\text { Sí, sólo } \\
\text { en alguna } \\
\text { comunidad } \\
\text { Autónoma }\end{array}$ \\
\hline México & $\begin{array}{l}\text { Agresiones físicas y } \\
\text { económicas, sexuales } \\
\text { por delincuencia } \\
\text { organizada }\end{array}$ & $\begin{array}{l}\text { Emigración a } \\
\text { Estados Unidos }\end{array}$ & $\begin{array}{l}\text { Si, del Estado, } \\
\text { religiosos y civiles }\end{array}$ & Sí & $\begin{array}{l}\text { Gratuito por } 90 \\
\text { días (Seguro } \\
\text { Popular) }\end{array}$ & $\begin{array}{l}\text { Sí, en } \\
\text { instituciones } \\
\text { específicas }\end{array}$ \\
\hline Nicaragua & $\begin{array}{l}\text { Violencia sexual, } \\
\text { acentuada en la } \\
\text { infancia }\end{array}$ & $\begin{array}{l}\text { Emigración a } \\
\text { Estados Unidos }\end{array}$ & $\begin{array}{l}\text { Si, del Estado, } \\
\text { religiosos y civiles }\end{array}$ & No & Gratuito & Sí \\
\hline Panamá & No & Sin datos & $\begin{array}{l}\text { Si, del Estado, } \\
\text { religiosos y civiles }\end{array}$ & No & $\begin{array}{l}\text { Gratuito en los } \\
\text { albergues para } \\
\text { migrantes }\end{array}$ & $\begin{array}{l}\text { Sí, en } \\
\text { instituciones } \\
\text { específicas }\end{array}$ \\
\hline Paraguay & $\begin{array}{l}\text { Violencia sexual y } \\
\text { trata de blancas }\end{array}$ & Sin datos & No & No & $\begin{array}{l}\text { En emergencia } \\
\text { médica o } \\
\text { quirúrgica }\end{array}$ & Sí \\
\hline Uruguay & $\begin{array}{l}\text { Actitudes } \\
\text { agresivo-pasivas }\end{array}$ & Sin datos & No & No & $\begin{array}{l}\text { En emergencia } \\
\text { médica o } \\
\text { quirúrgica }\end{array}$ & $\begin{array}{l}\text { Sí, en } \\
\text { instituciones } \\
\text { específicas }\end{array}$ \\
\hline Venezuela & No & Sin datos & No & No & $\begin{array}{l}\text { En emergencia } \\
\text { médica o } \\
\text { quirúrgica }\end{array}$ & No \\
\hline
\end{tabular}

Fuente: Datos obtenidos de la investigación según referencias. . $^{3,10,22,28,36,60,73-106,119-131}$

Mujer Migrante: Ofrece servicios de comunicación e información confiable y oportuna para mujeres migrantes y sus familias -en México y en el extranjero, principalmente en EUA, así como extranjeros establecidos o en tránsito por México, en particular de Centroamérica-, a fin de reducir los riesgos de su condición de doble vulnerabilidad: mujeres y migrantes. ${ }^{91}$

Programa Temporal de Regularización Migratoria: La finalidad es regularizar la situación del inmigrante temporal en México. ${ }^{92}$ 
Seguro Popular: La Comisión Nacional de Protección Social en Salud facilita a los indocumentados su incorporación temporal al Sistema de Protección Social en Salud del Seguro Popular por 90 días, durante su tránsito por el territorio nacional, cubriendo los tres niveles de atención médica, no importando su estatus de migrante regular o irregular. ${ }^{93}$

Vete sano, regresa sano: Es un programa que contribuye con la salud de los migrantes y sus familias con acciones intersectoriales de promoción y prevención de la salud, en el lugar de origen, tránsito y destino de estos grupos, principalmente en EUA y ciudades más importantes de emigración. ${ }^{3}$

Otros países como Paraguay, Uruguay, Nicaragua y Venezuela, cuentan con legislaciones que garantizan el derecho a la salud para toda la población, incluyendo a los migrantes, sin embargo, no cuentan con programas específicos. Bolivia legalmente tiene la posibilidad de apoyar a los migrantes regulares, en algunos programas prioritarios como la atención del parto, atención infantil o del anciano, como se verá más adelante.

En España, el Real Decreto Ley (RDL) 16/2012 excluyó de la asistencia sanitaria a miles de personas incluyendo a los migrantes en tránsito, salvo en algunas situaciones como atención de urgencias o atención a embarazadas, menores, solicitantes de asilo, víctimas de trata, sin embargo, las vulneraciones de la ley incluso a estas poblaciones que sí tenían derecho reconocido han sido denunciadas por organizaciones como REDER y otras Organizaciones no Gubernamentales (ONG). ${ }^{94}$

\section{Acceso a la atención médica para personas inmigrantes indocumentadas}

En la mayor parte de los países como Colombia, Chile, Uruguay, Paraguay y Venezuela se brinda atención médica a los inmigrantes en caso de emergencia médica o quirúrgica, aun en caso de situación irregular, quedando cubiertos los gastos a cargo del Estado. ${ }^{28,95-97}$ España, a través del Real Decreto (RD) 1192/2012 y Real Decreto Ley 16/2012: En su artículo 8 recoge que los extranjeros no comunitarios que se encuentren en España inscritos en el Registro de Residentes Extranjeros o sean residentes en situación administrativa regular, tienen derecho a la asistencia sanitaria en las mismas condiciones que los españoles. Así mismo, los extranjeros no registrados ni autorizados como residentes en España (inmigrantes en situación administrativa irregular), recibirán asistencia sanitaria solo en las siguientes situaciones: a) Por urgencia debida a enfermedad grave o accidente, cualquiera que sea su causa, hasta la situación de alta médica, b) Por embarazo, parto y postparto y c) Los menores de dieciocho años recibirán asistencia sanitaria en las mismas condiciones que los españoles. ${ }^{98,99}$ No obstante la existencia del RD, no todas las comunidades lo aplican tal cual, en Cataluña, Euskadi y Asturias, se les garantiza el derecho a recibir asistencia sanitaria si se encuentran empadronados dentro de su territorio. En Castilla - La Mancha, se les facturan los gastos por la atención prestada. Solo en Andalucía se presta asistencia sanitaria a los inmigrantes en situación irregular en las mismas condiciones que al resto de los españoles. ${ }^{100,101}$

En el caso de Brasil, Ecuador y Nicaragua, el servicio médico se presta de forma indistinta a cualquier persona que lo solicite, independientemente de la ciudadanía o situación migratoria. Este hecho ha motivado que en el caso de Nicaragua, muchas personas, incluyendo los ciudadanos hondureños, crucen la frontera sólo para recibir atención sanitaria y regresar a su país. ${ }^{36,90}$ En los casos de México y Panamá 
reportaron que además de brindar la protección a la salud de los migrantes irregulares, también cuentan con albergues que brindan asistencia temporal en cuestiones básicas como alimentación, vivienda, vestido y asesoría legal. ${ }^{93,102}$

\section{La atención del migrante irregular que no puede pagar el servicio médico}

En algunos países como Argentina, Brasil, Ecuador, Nicaragua y Paraguay, la atención médica para migrantes irregulares es gratuita. ${ }^{90,103}$ En Panamá puede brindarla de esta manera solo en los albergues, mientras que Chile y Uruguay lo hacen sólo en los casos de estar afiliados al Fondo Nacional de Salud (FONASA), en el primer caso o alguna mutualista en el segundo. ${ }^{104-106}$ Colombia y España sólo si se trata de emergencias médicas o gineco-obstétricas que ya se han mencionado antes. ${ }^{99,107}$ México por 90 días a partir de su registro en el Seguro Popular gratuito ${ }^{93}$ y Bolivia lo hace en la seguridad social de manera informal, previa autorización del director de la unidad médica, ya que de manera formal sólo se puede brindar atención a migrantes regulares que no cuenten con seguros de salud y en las siguientes áreas: mujeres embarazadas, niños menores de 5 años, adultos mayores a partir de los 60 años, servicios de salud sexual y reproductiva a mujeres en edad fértil y a personas con discapacidad. ${ }^{108}$ En Venezuela recientemente se ha limitado esa posibilidad al condicionarse la atención médica a la presentación del "Carnet de la Patria.

\section{En caso de que el migrante no pueda comprar el medicamento}

En cuanto a proporcionar los medicamentos de forma gratuita para los migrantes, llama la atención que diez de los trece países, lo pueden proporcionar bajo diferentes características. Argentina, Brasil, Ecuador, Nicaragua y Paraguay lo hacen de forma indistinta con sus ciudadanos en las instituciones públicas de salud y dentro de un cuadro básico de medicamentos. ${ }^{90,109}$ Mientras que Bolivia lo proporciona sólo a los migrantes regulares y en los programas referidos en el párrafo anterior. España, sólo en alguna comunidad autónoma. ${ }^{99}$ Chile, México, Uruguay y Panamá sólo en determinadas instituciones de salud. ${ }^{91,104-106}$ Los países que no proporcionan medicamentos a migrantes irregulares son Colombia y recientemente Venezuela, que puede explicarse por las circunstancias de crisis económica, política y social que vive actualmente.

\section{Principales problemas de salud por lo que consulta la población inmigrante}

Los principales motivos de consulta a los servicios de salud en los 13 países encuestados se repiten con relativa frecuencia. Por lo que serán presentados en dos dimensiones, según la información recibida: la esfera biológica y la de salud mental.

En el área de enfermedades biológicas, las más frecuentes fueron las respiratorias y gastrointestinales y otras infecciosas como la tuberculosis, hepatitis, las transmitidas por vectores, huéspedes y reservorios como el paludismo, dengue, filariasis, esquistosomiasis; además de los accidentes y lesiones. Estas afecciones resultaron un común denominador para Bolivia, España, México y Argentina, aunque este último también refiere como frecuente las cefaleas alergias, problemas vasculares, desde la insuficiencia vascular, hasta los accidentes vasculares cerebrales. ${ }^{76,102,109-113}$ Bolivia también reporta alta frecuencia de "mal de altura" ${ }^{110}$ Para Chile, las principales demandas de atención médica son las enfermedades que requieren intervención quirúrgica (37\%), parto (20\%), enfermedad con tratamiento médico (18\%) y embarazo $(5,8 \%) .{ }^{28}$ 
Los problemas de salud mental reportados con mayor frecuencia son los siguientes:

Nicaragua destacó que las personas consultadas y con familiares migrantes sufren estrés (67\%), depresión (58\%), dolor de cabeza (39\%) y violencia intrafamiliar (5\%). ${ }^{11,115}$ Brasil menciona que los inmigrantes con más desórdenes mentales y del comportamiento son los coreanos de São Paulo: trastornos de ansiedad (13\%), trastorno de estrés postraumático $(9,6 \%)$, trastornos del humor $(8,6 \%)$, trastornos somatoformes $(7,4 \%)$, trastornos disociativos $(4,9 \%)$, trastornos psicóticos $(4,3 \%)$, trastornos alimentarios $(0,6 \%)$, trastornos derivados de sustancias psicoactivas (alcohol, tabaco o drogas, $23,1 \%)$. Estos pacientes coreanos presentan más trastornos psiquiátricos que la población en Corea, especialmente trastorno de estrés postraumático, y una tasa similar a la encontrada en la población brasileña. ${ }^{116}$ Argentina, además de los problemas orgánicos ya referidos, también menciona que $33 \%$ de los pacientes migrantes encuestados, que se atienden en un hospital de la Ciudad de Buenos Aires, presentaron estrés aculturativo, también llamado Síndrome de Ulises, con datos de somatización. Finalmente, Uruguay reportó que no hay diferencias entre la patología de los inmigrantes y la morbilidad nacional. Colombia, Panamá y Venezuela no tienen información disponible al respecto.

\section{Servicios médicos más utilizados por los inmigrantes irregulares en los Sistemas de Salud}

Al preguntar acerca de la utilización de los servicios médicos por parte de los inmigrantes, doce de los 13 países reportaron no contar con información oficial al respecto, no obstante, con base a la investigación realizada por los integrantes del grupo de trabajo entre sus colegas interinstitucionales, y por la experiencia personal de cada uno de ellos, refirieron que los servicios de primer nivel de atención y urgencias son los más demandados, seguidos probablemente por servicios de gineco-obstetricia y pediatría, así como de salud pública, para el control y tratamiento de las principales causas de demanda de atención médica referidas en el apartado anterior. Se conoce también que existen centros de asistencia para los migrantes proporcionados por diferentes instituciones de tipo religioso, fundaciones, ONG, entre otras. España respondió que los inmigrantes irregulares no tienen acceso al sistema sanitario desde 2012. Los inmigrantes regularizados tienen los mismos derechos que los ciudadanos españoles. Dicho esto, los servicios más utilizados por los inmigrantes están relacionados con las necesidades de salud materno-infantil. ${ }^{99,117,118}$

\section{Los albergues para migrantes irregulares en tránsito}

Los albergues para migrantes irregulares se constituyen como refugios y "puestos de control sanitario y legal" (aunque no es su principal función), que permiten a las personas sobrevivir, reflexionar, incluso, insertarse laboral y socialmente al país anfitrión. En su mayoría les proporcionan alojamiento, alimentación, ropa, seguridad, asesoría jurídica, orientación general, apoyo espiritual y en muchos casos atención médica y psicológica. En los casos donde el albergue es del Estado, también se proporciona con frecuencia asistencia para retornar a sus lugares de origen. En el estudio que se presenta, sólo seis de los 13 países cuentan con albergues para migrantes financiados por los respectivos gobiernos, es el caso de Chile, Ecuador, España, México, Nicaragua y Panamá. Estos cinco países cuentan también con otros recintos que tienen el mismo objetivo, pero son de carácter religioso o civil, con financiamiento no gubernamental. ${ }^{119-124}$ Bolivia y Colombia, cuentan con albergues de este último tipo, principalmente de carácter religioso en donde no 
participa el Estado. ${ }^{125-128}$ En Ecuador, existen albergues para personas que esperan ser deportadas, uno de ellos está ubicado en un hotel de la capital que consta con todos los servicios básicos. ${ }^{129}$ Finalmente, cinco de los países encuestados, la mayoría del Cono Sur, Argentina, Brasil, Paraguay, Uruguay, y Venezuela, no cuentan con albergues que den soporte a la movilidad migratoria.

\section{Acerca de la migración infantil en IBA}

De los 13 países, sólo ocho proporcionaron información al respecto de la migración infantil en sus respectivos países. En el Cono Sur, Argentina, según el último Censo poblacional de 2010, existían en ese momento 140,312 menores de 14 años de nacionalidad extranjera. Además, en la composición de las solicitudes de asilo y refugio, $89 \%$ era mayor de edad y $11 \%$ infantes, predominando los hombres (65\%), no acompañados o separados de sus familias. ${ }^{10}$ Para Chile, la población inmigrante menor de 18 años corresponde a $1,4 \%$ del total, siendo el grupo de mayor presencia el de 20 a 35 años. ${ }^{28}$

En la Subregión Andina, Bolivia menciona que los reportes más recientes sobre inmigración infantil corresponden al Censo de Población y Vivienda 2001. En éste, se hace referencia a que en la amazonia boliviana los inmigrantes brasileiros menores de 15 años representan $40 \%$, los colombianos $16,4 \%$, ecuatorianos $19,2 \%$ y peruanos $14,3 \% .{ }^{60}$ Según el Observatorio de los Derechos de la Niñez y la Adolescencia (ODNA), en el 2010 el 1\% de la población de Ecuador menor de 18 años es originaria de otro país; este porcentaje corresponde al $27 \%$ del total de extranjeros. La mayor parte proviene de Colombia y, en número menor de Perú. ${ }^{130}$ Por su parte, Venezuela no dispone de información oficial de este tema, no obstante, según algunas fuentes no oficiales y reportajes de prensa, así como la observación cotidiana, se puede inferir que la mayoría de los inmigrantes, tanto en el pasado como en la actualidad, son adultos que llegan solos al país, siendo pocos los niños que ingresaron o ingresan en esta forma.

Por Mesoamérica, México y Nicaragua, reportan, que en el caso del primero, $1,5 \%$ y $1,6 \%$ de los niños de 0-9 años de edad (hombres y mujeres respectivamente) y 5,6\% y 5,7\% del grupo de 10-19 años (hombres y mujeres), fueron repatriados de EUA a México, descendiendo de 20,438 en 2010 a 11,743 en 2015. ${ }^{22}$ Para Nicaragua, entre octubre de 2013 y junio de 2017, la Patrulla fronteriza de EUA capturó a 16,546 menores no acompañados provenientes de Honduras, 14,086 de Guatemala y 13,301 de El Salvador, pero solamente a 178 de Nicaragua. El número de niños deportado de EUA a Nicaragua es menor con respecto a otros países vecinos, a pesar de las dificultades socioeconómicas que enfrenta el país. ${ }^{131}$

La inmigración infantil en España batió record en 2017, ya que en los nueve primeros meses se contabilizaron 5,380 menores extranjeros no acompañados en los centros de acogida de las comunidades y ciudades autónomas, 34,6 \% más que en todo 2016, cuando hubo 3,997. Las estadísticas del Gobierno central, revelan que a España llegaron desde 2014 un total de 16,379 menores inmigrantes.

\section{Los inmigrantes en el país receptor ¿viven solos o con su familia?}

Al respecto de la pregunta de si los inmigrantes viven solos o en familia en el país receptor, vemos que sólo fue respondida por cinco de los doce países (Argentina, Bolivia, España, México y Uruguay). Argentina reporta que en la actualidad, la estructura familiar de las familias inmigrantes es la siguiente: pareja e hijos $43,78 \%$, pareja sola $24,42 \%$, hijos solos $12,90 \%$, solos $11,06 \%$, padres y hermanos $0,92 \%$, 
padres $1,38 \%$ y otros $5,53 \%$. Por otra parte, los inmigrantes de países limítrofes han llegado mayormente cuando eran jóvenes, consecuentemente, una alta proporción de ellos y ellas no habían conformado aún sus familias de procreación antes de partir. Mayormente residían con sus padres y sólo una minoría tenía cónyuge e hijos. Si bien son numerosas las mujeres inmigrantes que ya son madres, es bastante baja la proporción de quienes tienen a sus hijos en el país de origen (madres a larga distancia). Esta práctica es muy poco común entre las mujeres de origen boliviano y más difundida entre aquellas de origen paraguayo. ${ }^{103}$

En cuanto a la composición familiar, según datos proporcionados por Bolivia, en el Censo Nacional de Población y Vivienda 2001 (no se encontraron datos más recientes), 43,3\% de los extranjeros nacidos en países amazónicos (Brasil, Perú, Colombia, Venezuela, Ecuador) fueron solteros, $51 \%$ casado/conviviente y $5,8 \%$ separado/viudo/divorciado. ${ }^{60}$

En España, la población inmigrante vive de la siguiente manera: $33 \%$ solo (35\% de los hombres, $31 \%$ de las mujeres); $28 \%$ con otra persona; $27 \%$ en unidades de 3-4 personas; y el restante $12 \%$ en unidades de más de 4 personas. El tamaño medio de los hogares es de 2,5 miembros, por debajo del promedio de los hogares españoles (2,8 según el Censo de 2001). ${ }^{132}$

En el caso de México, se menciona que según el Censo de población de 2010 (el último), 54,4\% de los inmigrantes estaban casados y $45.6 \%$ solteros. $^{35}$

La información proporcionada por Uruguay no es de carácter nacional, corresponde al reporte de un Centro de salud de Montevideo, según el cual, $75 \%$ de los registros de pacientes migrantes atendidos de enero a julio 2016, llegaron solos, siendo una amplia mayoría mujeres (cerca del 100\%).

\section{Población emigrante que vive sola, sin volver a unirse a otra pareja}

Esta pregunta sólo fue respondida por seis de los trece países, Bolivia, Ecuador, España, México, Nicaragua y Uruguay. El primero menciona que la presencia de solteros es equiparable a la de casados (35\%), con una notable presencia de parejas en cohabitación (24\%). ${ }^{42}$ En Ecuador según la Encuesta de Empleo y Desempleo de 2006, registra que, en lo referente al estado civil de las personas que abandonaron el país, $48.1 \%$ tienen un compromiso (casado/a $42.3 \%$ y unión libre 5.8\%), destacando en este grupo los hombres con porcentajes de $49.6 \%$. Mientras que en aquella población que no tenían cónyuge (separado/a $2.9 \%$, divorciado/a $2.0 \%$, viudo/a $1.3 \%$, soltero/a $45.7 \%$ ) destacan las mujeres con el $53.8 \%{ }^{133}$

España, reporta que de las personas casadas, $38 \%$ de los hombres y $26 \%$ de las mujeres se hallan separadas físicamente de sus cónyuges, en la mayoría de los casos porque no han logrado la reunificación en España. Por otra parte, $62 \%$ de los padres inmigrantes y $47 \%$ de las madres tienen hijos en el país de origen (de ellos, más de dos tercios son menores de edad). La reunificación de los cónyuges es algo mayor entre los europeos del este y los latinoamericanos (73\% en ambos casos) que entre los africanos (66\%). Sin embargo, debido a que la inmigración africana es más antigua en España y tienen más hijos de promedio (2,5, por 1,6 de los europeos del Este y 1,9 los latinoamericanos), el tamaño medio tanto de sus hogares (2,8 miembros) como de sus viviendas (4,8 miembros) es mayor que el de los otros grupos (2,3 y 4,2 los europeos y 2,4 y 4,1 los latinos). Por último, la tasa de natalidad más elevada de los latinoamericanos, en relación a los europeos del este, explica que el tamaño medio de sus hogares sea mayor a pesar de que el grado de reunificación familiar es similar en ambos grupos. ${ }^{132}$ 
En México, se reporta que la estructura familiar de los inmigrantes del sexo femenino que no se volvió a casar o unir en pareja fue de 9,4\% y los hombres de 10,8\% en $2010 .{ }^{22}$

En Nicaragua el fenómeno de la emigración trajo como resultado que las familias hayan pasado de ser nucleares a monoparentales y en muchos casos a ser familias extendidas; la mayoría de las veces son las madres solteras quienes emigran dejando a cargo de sus hijos e hijas a otros familiares. Se estima que prácticamente la mitad de los 900 mil nicaragüenses que residen en el exterior dejaron hijos e hijas en su país de origen. ${ }^{134}$

Por último, en el caso de Uruguay, el reporte corresponde a información del centro de Salud Ciudad Vieja, mencionando que $72 \%$ de los inmigrantes que se atendieron viven solos o agrupados sin sus familias que quedaron en su país de origen.

\section{Tipo de servicios médicos que ofrece el médico familiar a migrantes}

En general, la actuación de los médicos de familia en los trece países es muy similar, está enfocada a la atención de los pacientes desde la perspectiva de la medicina familiar y la atención primaria, con actividades basadas en el enfoque de riesgo, atención integral y continua, en muchos casos con actividades de rehabilitación y de vigilancia epidemiológica. No obstante, ninguno de los países menciona tener programas asistenciales propios para la salud de los migrantes debidamente estructurados.

\section{El rol del médico familiar o general en la salud de los migrantes}

En cuanto al rol del médico familiar o general en los sistemas de salud de IBA, sólo España tiene definido el rol del profesional en la atención de la salud de los migrantes. Doce de los 13 países dan el mismo trato en la atención de estos pacientes que a cualquier otro ciudadano de su país. No obstante, las determinantes sociales de la salud en los migrantes no son consideradas ni tampoco los factores de movilidad y riesgos de su condición migratoria. En este sentido, España puntualiza que es necesario individualizar y personalizar la atención al paciente inmigrante. Una historia clínica que incluya los aspectos relacionados con el proceso migratorio y una exploración física cuidadosa para llegar al diagnóstico en estos pacientes. La atención a los inmigrantes presenta algunas diferencias respecto de los pacientes autóctonos, sobre todo en las primeras etapas de su llegada y siempre teniendo en cuenta el país de procedencia y el tiempo de estancia en el país receptor. ${ }^{111,135}$

También el médico de familia debe aconsejar y realizar actividades de prevención y promoción de la salud cuando el inmigrante vaya a regresar al país de origen (consejería, vacunaciones, profilaxis antipalúdica, etc.). Además, en el abordaje holístico de los pacientes, es importante la atención de los aspectos psicológicos, socioculturales y religiosos que pueden influir sobre la salud del paciente y su familia, debiendo recordar que el proceso migratorio es un acontecimiento vital y estresante, debiendo estar atento a la presentación de cuadros psiquiátricos graves. ${ }^{111,135}$

En resumen, el médico familiar cuando atiende a inmigrantes, su objetivo debe ser una atención médica culturalmente apropiada, eficiencia clínica culturalmente competente, respetuosa, flexible y sensible. ${ }^{111,135}$ 


\section{El tema de la salud de los migrantes se encuentra dentro del currículo de la Carrera de Medicina o del posgrado de Medicina Familiar}

De los 13 países encuestados, sólo España tiene un programa formal de Salud de los Migrantes en el currículo de la especialidad de Medicina Familiar, ${ }^{136}$ cuyas competencias están dirigidas al manejo de comunicación efectiva con esta población y a la atención de los riesgos de enfermedades infecciosas e importadas, así como a situaciones de riesgo familiar y social, tales como personas en exclusión social, pacientes discapacitados, violencia familiar, etc.

En algunos programas de especialización en Medicina Familiar de Ecuador y México, existen módulos o temas destinados a la asistencia de los migrantes y sus familias, enfatizando en la adopción de competencias lingüísticas, comunicación e interculturalidad, desde el enfoque holístico propio de la especialidad.

Por su parte, Argentina, que al igual que los otros doce países no cuenta con un programa formal en la carrera de Medicina o en la especialidad de Medicina Familiar, ha desarrollado desde 2007 el grupo de trabajo: Salud y Migraciones, dependiente de la Dirección de Docencia, Investigación y Desarrollo Profesional del Ministerio de Salud del Gobierno de la Ciudad Autónoma de Buenos Aires, los cuales realizan capacitaciones denominadas "Formación de Formadores: Curso Migraciones, Salud e Interculturalidad. Concepciones y prácticas”. A partir de 2010, se formalizó como actividad de educación continua posgraduada, alcanzando en este momento siete ediciones. ${ }^{137}$

\section{Respecto de la salida de emigrantes sanos y su retorno al país de origen enfermos}

Ningún país tiene información al respecto, no obstante que no es posible documentar este hecho, resulta fácil de comprender que en muchos de los países que reciben inmigrantes, lo hacen como capital humano de excepcional calidad, jóvenes, fuertes, motivados, decididos, etc., sin embargo, después de estar por años en la informalidad y expuestos a explotación, jornadas de trabajo superiores a las aprobadas por ley, con determinantes sociales en contra de su salud y sin acceso formal a los servicios sanitarios y sistemas de protección social, resulta evidente que muchas personas que emigraron retornan a sus países enfermos y envejecidos, para ser atendidos por los sistemas de salud que les tiene en garantía su país de ciudadanía, convirtiéndose en una carga social.

\section{Respecto de la salida de emigrantes sin adicciones y que las haya adquirido en el país huésped}

Al respecto del complicado tema de las adicciones importadas a través de la migración, ningún país tiene información puntual que pueda proporcionar una idea clara de la situación. España es el país que de forma indirecta puede aportar algunos datos generados a través de la epidemiología del SIDA. En este sentido, se ha observado que si bien los mecanismos de transmisión implicados en la transmisión de la enfermedad, corresponden a los de sus países de origen, siendo los contactos sexuales no protegidos la principal vía de infección en el colectivo inmigrante. Destaca el hecho de que $41 \%$ de los casos en personas originarias de África del Norte se habían infectado a través del uso de drogas por vía parenteral, mecanismo que es poco común en los países de origen, pero sí es frecuente en España. Este dato sugiere 
que muchas de las conductas de riesgo para la infección se adquieren en ese país y apoyan la hipótesis de que al menos $25 \%$ de los inmigrantes con SIDA se han infectado debido a esa situación de vulnerabilidad socioeconómica, cultural y afectiva. ${ }^{135}$

En otro ámbito como el de la prostitución ejercida por mujeres inmigrantes en España, la cual es producto de la necesidad de obtener ingresos; la ausencia de protección familiar, personal y social; la explotación y tráfico sexual, entre otras. Resulta fácil comprender que los riesgos a la salud no sólo los constituyen las infecciones de transmisión sexual, también se ha reportado que existe una relación importante con otras enfermedades y trastornos psicológicos y psiquiátricos como la ansiedad, depresión, somatizaciones, trastornos de conducta, trastornos psicóticos y el estrés postraumático; además de la automedicación y adicciones (alcohol, cocaína y marihuana), las cuales no suelen ser reconocidas, por lo que es difícil de cuantificar. ${ }^{135}$

Asimismo, las mujeres inmigrantes son más vulnerables a la violencia de pareja, dada su situación de indefensión, pudiendo presentar efectos más devastadores por la cronicidad, el silencio, el deterioro y ausencia de recursos sociales paliativos. Dicha situación puede dar lugar al deterioro de su salud mental con depresión, ansiedad, trastornos del sueño, lo que también conlleva riesgo de adicciones como abuso del consumo de alcohol y barbitúricos, u otros medicamentos. ${ }^{135}$

\section{Conclusiones}

La investigación realizada permite observar que existen grandes carencias en los mecanismos de recolección de datos a nivel de las instituciones de salud y de otras vinculadas con el fenómeno de la migración, en la mayor parte de los países participantes. Al analizar la información recogida en el cuestionario y el origen de la misma, resulta obvio que las fuentes bibliográficas consultadas por los investigadores participantes son múltiples y muy disímiles, no comparables entre sí (censos, encuestas internas, investigaciones particulares, registros de organizaciones, entrevista, experiencia personal, otros), lo en algunos casos pudieran considerarse un tanto subjetivos. No obstante, estas limitaciones y alcances, la información presentada fue muy bien documentada y permite hacer los comentarios que a continuación se exponen.

El tema de migración y los servicios de salud en Iberoamérica debe ser un tema prioritario en la agenda política de los gobiernos, de las instituciones de salud, de las universidades y de todos y cada uno de los profesionales en medicina familiar y proveedores de servicios de atención primaria.

Resulta importante destacar, la falta de preparación de los recursos humanos en medicina familiar y atención primaria, en el tema de la salud del migrante, lo que constituye un reto urgente a resolver, dada la gran responsabilidad que guardan los gobiernos en materia de control y vigilancia epidemiológica, además de ser la salud un derecho fundamental de todo ser humano. Eso sin mencionar la importancia económica de la migración en la mayor parte de los países, así como de la riqueza cultural y humana que aportan a las sociedades.

También se concluye, que el acceso y cobertura de la población migrante (sobre todo la irregular), es muy deficiente en la mayor parte de los países, incluso, en los que pudieran tener una estructura sanitaria más sólida, generando mayores riesgos a la salud, no sólo para los migrantes, sino también, de la población general. 
Debido a la falta de información comentada previamente, no se pudo dar respuesta a algunas de las interrogantes, lo que limita la interpretación de los datos, no obstante, la investigación realizada por los integrantes del grupo de trabajo en las instituciones de salud de sus países (cualitativa), puede dar soporte a los resultados que se presentan, aunque será importante profundizar con investigaciones más puntuales, en cada uno de los países de la Región.

Finalmente, los resultados presentados en este documento fueron analizados y discutidos en mesas de trabajo durante la VII Cumbre Iberoamericana de Medicina Familiar, llegando en consenso de los representantes de los 17 países participantes en las mesas de trabajo a las siguientes recomendaciones:

I. Reconocer el derecho a la salud de las personas migrantes y sus familias, asegurando el acceso igualitario de protección, amparo, y derechos que gozan los ciudadanos de cada país.

II. Incorporar en la malla curricular de los programas de pregrado, posgrado y formación continua, las competencias necesarias para la atención integral de la población migrante y de sus familias.

III. Creación de un observatorio de salud de la migración, con registro de información confiable y validada, que permita análisis y seguimiento para la toma de decisiones efectivas y centradas en las personas y sus familias.

\section{Referencias}

1. Oliva J, Pérez G. Inmigración y salud. Gac Sanit. 2009; 23(Supl 1):1-3. http://dx.doi.org/10.1016/j.gaceta.2009.10.002

2. Ceja FA, Lira MJ, Fernández GE. Salud y enfermedad en los migrantes internacionales México-Estados Unidos. Ra Ximhai. 2014; 10(1):291-306.

3. Instituto de Salud del Estado de México, Secretaría de Salud. Vete sano, regresa sano. México, 2017. [Consultado 25 octubre 2017]. Disponible en: http://salud.edomexico.gob.mx/html/vete_sano.htm\#

4. Castro N. Los flujos migratorios en América Latina. Esglobal 2016. [Consultado 25 octubre 2017]. Disponible en: https://www.esglobal. org/los-flujos-migratorios-intrarregionales-en-america-latina/

5. Aumenta la inmigración intrarregional en Iberoamérica. Notiamérica. Madrid. 2017. [Consultado 25 octubre 2017]. Disponible en: http:// www.notimerica.com/sociedad/noticia-aumenta-inmigracion-intrarregional-iberoamerica-20170529194012.html

6. Observatorio Iberoamericano sobre Movilidad Humana, Migraciones y Desarrollo. Las migraciones en las fronteras en Iberoamérica. Madrid: Comillas. 2016.

7. Datosmacro.com [Internet]. España: web de servicios [consultado 27 enero 2018]. Disponible en: https://www.datosmacro.com/

8. Organización Internacional para las Migraciones. Los términos clave de migración. 2017. [Consultado 20 octubre 2017]. Disponible en: https://www.iom.int/es/los-terminos-clave-de-migracion

9. Organización Internacional para las Migraciones. Migración y Salud, Sección 2.7. 2017. [Consultado 25 octubre 2017]. Disponible en: http://www.crmsv.org/documentos/IOM_EMM_Es/v2/V2S07_CM.pdf

10. Benencia R. Perfil migratorio de Argentina 2012. Buenos Aires: Organización Internacional para las Migraciones. 2012

11. Censo demográfico 2010. Características da População e dos Domicílios. Brasil. [Consultado 7 febrero 2018 ]. Disponible en: https:// sidra.ibge.gov.br/pesquisa/censo-demografico/demografico-2010/universo-caracteristicas-da-populacao-e-dos-domicilios

12. Martínez PJ, Cano CV, Soffia CM. Tendencias y patrones de la migración latinoamericana y caribeña hacia 2010 y desafíos para una agenda regional.Serie Población y Desarrollo № 109. Santiago de Chile: Naciones Unidas. 2014.

13. Programa de Población-FCS-UdelaR. Perfil Migratorio de Uruguay 2011. Buenos Aires: Organización Internacional para las Migraciones. 2011.

14. Molina F. Migración: así estamos en Bolivia. Página siete. Bolivia. 25 junio 2017. [consultado 6 febrero 2018]. Disponible en: http://www. paginasiete.bo/ideas/2017/6/25/migracion-estamos-bolivia-142061.html 
15. Vega-Macías D. Migración y recesión económica: tendencias recientes en el saldo y los flujos de migrantes latinoamericanos y caribeños en España. Notas de Población № 104. enero-junio de 2017. Págs. 215-235. [Consultado 26 abril 2018] Disponible: https://www.cepal. org/es/publicaciones/41967-migracion-recesion-economica-tendencias-recientes-saldo-flujos-migrantes

16. International Organization for Migration. WORLD MIGRATION REPORT 2018. OIM. [Consultado 26 abril 2018] Disponible en: https:// publications.iom.int/system/files/pdf/wmr_2018_en.pdf

17. International Organization for Migration: IOM Migration Activities Bolivia. OIM. 2017. [Consultado 26 abril 2018] Disponible en: https:// www.iom.int/countries/bolivia

18. Viventa. Colombianos en el exterior. ¿Cuántos somos y dónde vivimos? 25 febrero 2016. Viventa. [consultado 7 febrero 2018]. Disponible en: https://viventa.co/colombianos-en-el-exterior-quienes-somos-cuantos-somos-y-en-donde-vivimos/

19. Ramírez C, Mendoza SL. Perfil migratorio de Colombia 2012. Bogotá: Organización Internacional para las Migraciones. 2013

20. Organización Internacional para las Migraciones. Tendencias migratorias en América del Sur. Informe Migratorio Sudamericano № 1. OIM. 2017

21. Organización Internacional para las Migraciones. Tendencias migratorias Nacionales en América del Sur. República Bolivariana de Venezuela. OIM. 2018.

22. Consejo Nacional de Población, Fundación BBVA Bancomer, BBVA Research. Anuario de Migración y Remesas. México 2017. CONAPOFundación BBVA Bancomer-BBVA Research. 1ra edición. México. 2017.

23. Baumeister E, Fernández E, Acuña G. Estudio sobre las migraciones regionales de los nicaragüenses. Guatemala: Editorial de Ciencias Sociales. 2008

24. Migración y Fecundidad 2010. 2011. Volumen V. Contraloría General de la República de Panamá. Instituto Nacional de Estadística y Censo. [consultado 5 febrero 218]. Disponible en: http://www.contraloria.gob.pa/inec/Publicaciones/subcategoria.aspx?ID_CATEGORIA=13\&ID_ SUBCATEGORIA=59\&ID_IDIOMA=1

25. Molina C. La emigración española toca máximos históricos. Cinco Días. El país. Madrid.15 marzo 2017. Economía. [consultado 5 febrero 218]. Disponible en: https://cincodias.elpais.com/cincodias/2017/03/15/economia/1489589762_376211.html

26. Organización Internacional para las Migraciones. Recientes tendencias migratorias extra e intra-regionales y extra-continentales en América del Sur. Informe Migratorio Sudamericano № 2. OIM. 2017

27. Yáñez C. Chile es el país latinoamericano donde más ha aumentado la inmigración. La tercera. Chile. 29/05/2017. [consultado 7 febrero 2018]. Disponible en: http://www2.latercera.com/noticia/chile-pais-latinoamericano-donde-mas-ha-aumentado-la-inmigracion/

28. Cabieses B, Bernales M, Mclntyre AM. La migración internacional como determinante social de la salud en Chile: evidencia y propuestas para políticas públicas. Chile. Universidad del Desarrollo. 2017

29. Departamento de Extranjería y Migración. DEM publica completo reporte sobre la población migrante en Chile. 15 enero 2018 . [consultado 7 febrero 2018]. Disponible en: http://www.extranjeria.gob.cl/noticias/2018/01/15/dem-publica-completo-reporte-sobre-la-poblacionmigrante-en-chile-2/

30. Organización Internacional para las Migraciones. Brasil. [consultado16 abril 2018]. Disponible en: https://robuenosaires.iom.int/brasil

31.Secretaria Nacional de Justiça. Refúgio em Números. Brasil. [consultado 6/02/2018]. Disponible en: http://www.justica.gov.br/news/ brasil-tem-aumento-de-12-no-numero-de-refugiados-em-2016/20062017_refugio-em-numeros-2010-2016.pdf

32. Instituto Nacional de Estadística. Argentina es el país de mayor preferencia de emigrantes bolivianos. Bolivia. 18 diciembre 2017. [consultado 6 febrero 2018]. Disponible en: https://www.ine.gob.bo/index.php/notas-de-prensa-y-monitoreo/itemlist/tag/Migraci\%C3\%B3n

33. Ramírez C, Zuluaga M, Perilla C. Perfil migratorio de Colombia. Bogotá: Organización Internacional para las Migraciones. 2010

34. Herrera MG, Moncayo MI, Escobar GA. Perfil Migratorio del Ecuador 2011. Organización Internacional para las Migraciones. 2012

35. Consejo Nacional de Población, Fundación BBVA Bancomer, BBVA Research. Anuario de Migración y Remesas. México 2014. CONAPOFundación BBVA Bancomer-BBVA Research. 1 ra edición. México. 2014.

36. González BHJ. Perfil migratorio de Nicaragua 2012. Managua: Organización Internacional para las migraciones. 2013

37. Convenio centroamericano de libre movilidad.[Internet]. Wikipedia. 2017. [consultado 2 febrero 2018]. Disponible en: https://es.wikipedia. org/wiki/Convenio_centroamericano_de_libre_movilidad 
38. Zúñiga GL. Estudio migratorio de Nicaragua. En Bonnici G, Coria E, Girón SCL, Gatica G, Zúñiga L, Suazo ML, Ardón NV. Estudio comparativo de la legislación y políticas migratorias en Centroamérica, México y República Dominicana. México: INCEDES/Sin Fronteras IAP. 2011. p. 439-510.

39. España recibe cada vez más remesas, aunque sigue siendo un país emisor. eleconomista.es. España. 12 junio 2016 . [consultado 5 febrero 2018]. Disponible en: http://www.eleconomista.es/espana/noticias/7630521/06/16/Espana-recibe-cada-vez-mas-remesasaunque-sigue-siendo-un-pais-emisor.html

40. Banco Central de Nicaragua. Informe Remesas Familiares. I Trimestre 2017. 2017

41. Maldonado R, Cervantes J, Bonilla S. Las remesas hacia América Latina y el Caribe en 2016: Nuevo récord. Programa de Remesas e Inclusión Financiera. México. Centro de Estudios Monetarios Latinoamericanos. CEMLA, 2017.

42. Pereira MR. Perfil Migratorio de Bolivia. Buenos Aires: Organización Internacional para las Migraciones (OIM). 2011.

43. Acosta A. El aporte de las remesas para la economía ecuatoriana. Reunión de Expertos sobre Migración Internacional y desarrollo en América Latina y el Caribe. Naciones Unidas, México, 30 de noviembre - 2 de diciembre de 2005.

44. Astudillo G. Ecuador recibió más remesas el 2016. EL COMERCIO. Ecuador. 16 marzo 2017. Actualidad [consultado 19 enero 2018]. Disponible en: http://www.elcomercio.com/actualidad/bancocentral-ecuador-remesas-migrantes-economia.html

45. Urrea CJ. ¿Por qué se va la gente de Colombia? El tiempo. Blogs. Política directa. Colombia. 20 diciembre 2016. [consultado 7 febrero 2018]. Disponible en: http://blogs.eltiempo.com/politica-directa/2016/12/20/por-que-se-va-la-gente-de-colombia/

46. El desempleo y los bajos ingresos siguen siendo causas de migración. Periódico Digital de Investigación sobre Bolivia. PIEB. 12-10-2011. [consultado 6 febrero 2018]. Disponible en: http://www.pieb.com.bo/sipieb_notas.php?idn=6221

47. Arrieta S. Migraciones bolivianas: causas y razones de los desplazamientos andinos hacia Buenos Aires Argentina. wodpress. Personas Cooperando. 21 octubre 2011. [consultado 6 febrero 2018]. Disponible en: https://personascooperando.files.wordpress.com/2011/10/ arrieta2011_migracionbolivia_argentina.pdf

48. Chirino F, Jauregui M, Nelson J, Holwegg K. Huella Migratorias: duelo y religión en las familias de migrantes del Plan Tres Mil de la ciudad de Santa Cruz. La Paz: Fundación PIEB. 2010.

49. Chilenos en el Exterior. Donde viven, cuántos son y qué hacen los chilenos en el exterior. Santiago. Dirección para la Comunidad de Chilenos en el Exterior. Ministerio de Relaciones Exteriores, Instituto Nacional de Estadísticas. DICOEX, INE. 2005.

50. Sonia O. Migración en Paraguay. Monografías.com. [consultado 6 enero 2018] Disponible en: http://www.monografias.com/trabajos98/ migracion-paraguay/migracion-paraguay.shtml

51. Estos son los 10 países del mundo con más inmigrantes. BBC. Mundo. Noticias. 23 febrero 2017. [consultado 15 abril 2018]. Disponible en: http://www.bbc.com/mundo/noticias-internacional-39059460

52. Martínez CJA. Comparación entre emigración siglo XX y emigración actual. Emigración española en la actualidad. Blog. 16 de febrero de 2013. [consultado 15 abril 2018]. Disponible en: http://migracionespa.blogspot.mx/2013/02/comparacion-entre-emigracion-siglo-xx-y. html

53. Stefoni C. Perfil Migratorio de Chile. Buenos Aires: Organización Internacional para las Migraciones (OIM). 2011.

54. Migración internacional en las Américas: Cuarto informe del Sistema Continuo de Reportes sobre Migración Internacional en las Américas (SICREMI) OEA.2017. [consultado 4 febrero 2018]. Disponible en: https://es.scribd.com/document/367568833/Oea-Sicremi-2017Espanol-Web-Final

55. Cavalcanti L, Oliveira A, Tonhati T, Dutra D. (orgs). A inserção dos imigrantes no mercado de trabalho brasileiro. Relatório Anual 2015. Observatório das Migrações Internacionais; Ministério do Trabalho e Previdência Social/Conselho Nacional de Imigração e Coordenação Geral de Imigração. Brasília, DF: OB Migra, 2015.

56. Cerca de 28 mil estrangeiros recebem autorização para trabalhar no Brasil. 2017. Governo do Brasil. Economia. [consultado 6/02/2018] Disponível em:http://www.brasil.gov.br/economia-e-emprego/2017/02/cerca-de-28-mil-estrangeiros-recebem-autorizacao-para-trabalharno-brasil

57. Bravo J. Análisis del empleo inmigrante en Chile. Informe. Centro Latinoamericano de Políticas Económicas y Sociales. [consultado 7 febrero 2018]. Disponible en: http://www.clapesuc.cl/assets/uploads/2016/11/30-11-16-informe-laboral-inmigrantes-trim-ago-oct-2016. pdf 
58. Caracterización sociodemográfica y laboral de los trabajadores temporales extranjeros en Colombia: una mirada retrospectiva. Migración Colombia. Bogotá: Organización Internacional para las migraciones OIM. 2013.

59.Delgado C. 6 de cada 10 extranjeros que llegan a Bolivia viven en Santa Cruz. El deber. Séptimo Día. 16 julio 2017 [consultado 6 febrero 2018]. Disponible en: https://www.eldeber.com.bo/septimodia/6-de-cada-10-extranjeros-que-llegan-a-Bolivia-viven-en-SantaCruz-20170714-0083.html

60. Roosta M (coord.), Pereira MR, Vargas M, Domenech EE, Hinojosa GA, Pérez OA. Población y desarrollo. Bolivia y los fenómenos de la migración internacional. Bolivia. CIDES-UMSA. 2009.

61. Extranjeros en Ecuador. EL COMERCIO. Editorial. [consultado 19 enero 2018]. Disponible en: http://www.elcomercio.com/opinion/ editorial/migrantes-ecuador-tratadepersonas-migracion-extranjeros.html

62. Instituto Nacional de Estadística. Encuesta Nacional de Inmigrantes. En busca de trabajo y una mejor calidad de vida. Boletín informativo del Instituto Nacional de Estadística. INE.2009. [consultado 5 febrero 2018]. Disponible en: http://www.ine.es/revistas/cifraine/0109.pdf

63. Acuña GGE. La inmigración en Costa Rica: dinámicas, desarrollo y desafíos. San José. Proyecto Fondo OPEC-UNFPA 2005. [consultado 2 febrero 2018].Disponible en: https://www.ministeriodesalud.go.cr/gestores_en_salud/derechos\%20humanos/migracion/inmigracr.pdf

64. Morales GA. La Diáspora de la posguerra: regionalismo de los migrantes y dinámicas territoriales en América Central. $1^{\underline{a}}$ ed. San José. FLACSO, 2007.

65. Organización Internacional para las migraciones. Migración en el Paraguay. OIM. [consultado 4 febrero 2018]. Disponible en: http:// paraguay.iom.int/?q=es/node/15

66. Roncken T, Serrudo S, Cielo C, Alquizalet O, Céspede R. Migración internacional y desarrollo local en la zona sud de Cochabamba: realidades, desafíos y posibilidades. Resumen del Informe Preliminar de Investigación. Migración Internacional y Desarrollo Comunitario. 2008. [Consultado 26 abril 2018] Disponible: http://migrantedelsur.pieb.org/informeresumen.htm

67. Imaña G, Wásquez W. Migración: Aún son más los que se van de Bolivia. La Razón. Suplementos Especiales: Migración. La Paz. 10 agosto 2015. [consultado 6 febrero 2018]. Disponible en: http://www.la-razon.com/index.php?_url=/suplementos/especiales/Migracionvan-Bolivia_0_2323567684.html

68. Caballero Pons M, Filippi F. Dinámicas de la inmigración boliviana en la Comunitat Valenciana y en España. Fundación MUSOL. 2012. [Consultado 26 abril 2018] Disponible: http://www.musol.org/images/stories/archivos/2016/Dinamicas.pdf

69. Martínez PJ, Orrego RC. Nuevas tendencias y dinámicas migratorias en América Latina y el Caribe. CEPAL-Serie Población y Desarrollo № 114. Santiago: Naciones Unidas. 2016.

70. Cerrutti M, Maguid A. Migrantes sudamericanos en España: Tendencias recientes y perfil de sus migrantes. En: Cerrutti M, Maguid A, Díaz GA. Migrantes Sudamericanos en España: Panoramas y Políticas. Cuadernos migratorios $\mathrm{N}^{\circ}$ 1. Buenos Aires: Organización Internacional para las Migraciones, OIM. 2011. p. 11-115.

71. AFP. El drama de los niños ecuatorianos que parten solos a EEUU para buscar a sus papás. Los Andes. 4 noviembre 2014. [consultado 19 enero 2018]. Disponible en: http://losandes.com.ar/article/ninos-migrantes-de-ecuador-el-peligroso-viaje-a-eeuu-en-busqueda-desus-padres-818416

72. Mayo MG. Así son los españoles que emigran. Expansión.com. 01-07-2013. Economía y política. [consultado 9 febrero 2018]. Disponible en: http://www.expansion.com/2013/06/28/economia/1372413617.html

73. Subrayado Especial: el trabajo de los inmigrantes en Uruguay. Subrayado.com. 8 junio 2017. [consultado 9 febrero 2018]. Disponible en: https://www.subrayado.com.uy/subrayado-especial-el-trabajo-los-inmigrantes-uruguay-n67650

74. Salomón J. Los bolivianos son los más discriminados en Argentina. El País. Buenos Aires. 13 Nov 2015. [consultado 6 febrero 2018] Disponible en: http://elpaisonline.com/index.php/2013-01-15-14-16-26/local/item/194046-los-bolivianos-son-los-mas-discriminadosen-argentina

75. Defensoría del pueblo. Diagnóstico de bolivianos y bolivianas en España. La Paz. Defensoría del pueblo. 2012.

76. Buller AM, Vaca V, Stoklosa H, Borland R y C Zimmerman. Explotación Laboral, Trata y Salud de los Migrantes: Hallazgos en Diversos Países sobre los Riesgos y Consecuencias para la Salud de los Trabajadores Migrantes y las Víctimas de Trata. Organización Internacional para las Migraciones y London School of Hygiene \& Tropical Medicine. 2015

77. González MA. Inmigración, ¿oportunidad o amenaza? El mostrador. Blogs y opinión. 13 octubre 2017. [consultado 7 febrero 2018]. Disponible en: http://www.elmostrador.cl/noticias/opinion/2017/10/13/inmigracion-oportunidad-o- amenaza/ 
78. Redacción El Tiempo. Colombia es origen, tránsito y destino de trata de personas, según ONU. El Tiempo. 13 de enero de 2017. [consultado 8 febrero 2018]. Disponible en: http://www.eltiempo.com/justicia/cortes/trata-de-personas-en-colombia-41315

79. Fruttero A, Wennerholm C. Migración Nicaragüense: un análisis con perspectiva de género. Serie Cuadernos de Género para Nicaragua. Nicaragua. Banco Mundial. Banco Interamericano de Desarrollo. 2008

80. Universidad Pontificia de Comillas y OBIMID. Estudio: Migración y desarrollo en Iberoamérica. Organización Internacional para las Migraciones. 2017

81. Informe RAXEN. Racismo, Xenofobia, Antisemitismo, Islamofobia, Neofascismo y otras manifestaciones de Intolerancia a través de los hechos. Especial 2016. Discurso de Odio y Tsunami de Xenofobia e Intolerancia. Movimiento contra la Intolerancia. [consultado 5 febrero 2018]. Disponible en: www.informeraxen.es/wp-content/uploads/2017/03/RAXEN-Especial-2016.pdf

82. Castellano N. 500 incidentes racistas y xenófobos durante 2016. Cadena SER. Madrid. 21/03/2017. Sociedad. [consultado 16 abril 2018] Disponible en: http://cadenaser.com/ser/2017/03/20/sociedad/1490034920_008733.html

83. SINC. Los inmigrantes latinoamericanos condenados por maltrato en España poseen un 'clima social' más favorable a la violencia de pareja. SINC La Ciencia es noticia. Ciencias Sociales. 12 mayo 2015. [consultado 16 abril 2018]. Disponible en: http://www.agenciasinc.es/ Noticias/Los-inmigrantes-latinoamericanos-condenados-por-maltrato-en-Espana-poseen-un-clima-social-mas-favorable-a-la-violenciade-pareja

84. El derecho fundamental a la salud, negado a los inmigrantes en muchos países europeos. HERALDO. Salud. Madrid. 13 abril 2016. [consultado 16 abril 2018]. Disponible en: https://www.heraldo.es/noticias/suplementos/salud/2016/04/13/el-derecho-fundamental-saludnegado-los-inmigrantes-muchos-paises-europeos-842391-1381024.html

85. López RV. Desarrollo, migración y seguridad: El caso de la migración hondureña hacia Estados Unidos. Migr Desarro 2013;11(21):65105

86. Comisión Nacional de los Derechos Humanos. Informe especial sobre secuestro de migrantes en México. México. CNDH. 2011.

87. Guerrero-Ortiz M, Jaramillo-Cardona MC. Deportación y violación de los derechos del migrante en ambas fronteras. Convergencia 2015; 22(69):85-106

88. Dirección Nacional de Migraciones. Se presentó el Centro de Orientación a Migrantes y Refugiados. Buenos Aires. DNM. 18 de diciembre de 2017 [consultado 6 enero 2018]. Disponible en: http://www.migraciones.gov.ar/accesible/novedad.php? $\mathrm{i}=3880$

89. Secretaría Nacional del Migrante-SENAMI. 2010. UNICEF-Ecuador [consultado 19 enero 2018]. Disponible en: https://www.unicef.org/ ecuador/Boletin_29_Parte3.pdf

90. Ministerio de Relaciones Exteriores y Movilidad Humana. Ley Orgánica de Movilidad Humana del Ecuador. Registro Oficial. Año IV - № 938 Quito, lunes 6 de febrero de 2017.

91. Mujer migrante.mx. México. [consultado 2 febrero 2018]. Disponible en: http://mujermigrante.mx/

92. Instituto Nacional de Migración. Programa temporal de regularización migratoria. México. 4 julio 2017. [consultado 1 febrero 2018] Disponible en: https://www.gob.mx/inm/es/acciones-y-programas/programa-temporal-de-regularizacion-migratoria-90502

93. Secretaría de Salud. Otorgan seguro popular a migrantes. Prensa. México. 28 diciembre 2014. [consultado 2 febrero 2018]. Disponible en: https://www.gob.mx/salud/prensa/otorgan-seguro-popular-a-migrantes-7519

94. Informes de REDER. Red de Denuncia y Resistencia al RDL 16/2012. [consultado 5 febrero 2018]. Disponible en: https://reder162012. org/index.php?option=com_content\&view=article\&id=98\&ltemid=102

95. Afiliación al sistema general de seguridad social en salud de extranjeros y colombianos retornados. Ministerio de Salud y Protección Social. Bogotá. [consultado 5 febrero 2018]. Disponible en: https://www.minsalud.gov.co/proteccionsocial/Paginas/afiliacion-al-sistemade-seguridad-social-en-salud-de-extranjeros-y-colombianos-retornados.aspx

96. La Ley en tu lenguaje. IMPO. Centro de Información Oficial. Julio 2012. [consultado 5 febrero 2018]. Disponible en: http://www.impo.com. uy/migracion/

97. Organización Internacional para las migraciones, Fondo de Población de las Naciones Unidas. Los problemas de los migrantes y la necesidad de una política migratoria. OIM. UNFRA. Boletín № 4.2003. [consultado 5 febrero 2018]. Disponible en: http://www.unfpa.org. py/download/boletin4.pdf

98. Ministerio de Sanidad, Servicios Sociales e Igual. España. Real Decreto 1192/2012, 3 de agosto de 2012. BOE. Núm. 186, 04/08/2012, Páginas 55775-55786. [consultado 17 abril 2018]. Disponible en: http://sid.usal.es/idocs/F3/LYN17285/17285.pdf 
99. Jefatura del Estado. España. Real Decreto-ley 16/2012. 20 de abril de 2012. BOE Núm. 98, 24 de abril de 2012. Sec. I. Pag 31278-31312. [consultado 17 abril 2018]. Disponible en: https://www.boe.es/boe/dias/2012/04/24/pdfs/BOE-A-2012-5403.pdf

100. Gómez ZLJ. La asistencia sanitaria en España, especial referencia a la prestación sanitaria a los extranjeros en situación irregular después de la modificación operada por el Real Decreto-Ley 16/2012. Gabilex 2016. № 5. [consultado 17 abril 2018]. Disponible en: http://gabilex.castillalamancha.es/sites/gabilex.castillalamancha.es/files/pdfs/la_asistencia_sanitaria_en_espana_leopoldo_gomez. pdf

101. Lema TM. La reforma sanitaria en España: Especial referencia a la población inmigrante en situación administrativa irregular. Eunomía. Revista en Cultura de la Legalidad. Septiembre 2013-febrero 2014;(5):95-115.

102. Consejo Nacional de Población. Migración y Salud. Perspectivas sobre la población inmigrante. 1ra ed. México. CONAPO. 2016.

103. Cerrutti M. Diagnóstico de las poblaciones de inmigrantes en la Argentina. Buenos Aires. Dirección Nacional de Población; 2009.

104. FONASA. Realidad migrante en Chile. Chile. 1 Julio 2016. [consultado 7 de febrero de 2018]. Disponible en: https://www.fonasa.cl/ sites/fonasa/noticias/2016/07/01/realidad_migrante_en_chile.html

105. Sistema Nacional Integrado de Salud. Uruguay. Ley $N^{\circ} 18.211$ [consultado 17 abril 2018). Disponible en: http://www.paho.org/uru/ index.php?option=com_docman\&view=download\&category_slug=publicaciones-sistemas-y-servicios-de-salud\&alias=146-ley-18211-sistema-nacional-integrado-de-salud\&Itemid=307

106. Aran D, Laca H. Sistema de salud de Uruguay. Salud Publica Mex 2013;53 Suppl 2:S265-S274.

107. El Congreso de Colombia. Ley Estatutaria 1751 de 2015. Diario Oficial No. 49.427 del 16 de febrero de 2015. [consultado 17 abril 2018]. Disponible en: https://www.minsalud.gov.co/Normatividad_Nuevo/Ley\%201751\%20de\%202015.pdf

108. Ministerio de Salud de Bolivia, Ley 475 de 2013. [Consultada 26 abril 2018] Disponible: https://www.minsalud.gob.bo/2766-partosgratuitos-papanicolaou-sin-costo-bonos-para-gestantes-algunos-de-los-beneficios-que-gozan-las-mujeres-bolivianas

109. Ministerio de Salud. Medicamentos. Cobertura Universal de Salud. Buenos Aires, Argentina. [consultado 6 enero 2018]. Disponible en: http://186.33.221.24/medicamentos//

110. Guidebolivia.com. Enfermedades con riesgo. [consultado 6 febrero 2018]. Disponible en: http://www.guidebolivia.com/pratique/ es_maladie.htm

111. Vázquez-Villegas J, Fernández-García MR, Martín-Laso MA. Inmigración y Atención Primaria. En: Martín ZA, Cano PJF, Gené BJ. Atención primaria. Principios, organización y métodos en medicina de familia. España: Elsevier, 2014. p. 85-108

112. Gomes MJA. Neoliberalismo y salud en la frontera de México y Estados Unidos. El caso de la tuberculosis. Migr Desarro. 2008;(11):55-78.

113. Foladori G, Moctezuma M, Márquez H. La vulnerabilidad epidemiológica en la migración México-Estados Unidos. Migr Desarro. 2004;(3):19-44.

114. Van der LC, Maquieira CL. Migración saludable en América central. Organización Internacional para las Migraciones (OIM). 2012. [consultado 2 febrero 2018]. Disponible en: http://publications.iom.int/system/files/pdf/manual_referencia_1.pdf

115. El impacto de la migración en la familia. El nuevo diario. Managua. 31 agosto 2013. [consultado 2 febrero 2018]. Disponible en: https:// www.elnuevodiario.com.ni/nacionales/295625-impacto-migracion-familia/

116. Kang S, Razzouk D, de Mari JJ, Shirakawa I. The mental health of Korean immigrants in São Paulo, Brazil. Cad Saúde Pública. 2009;25(4):819-826. http://dx.doi.org/10.1590/S0102-311X2009000400013

117. Cots F, Castells X, Ollé C, Manzanera R, Varela J. Vall O. Perfil de la casuística hospitalaria de la población inmigrante en Barcelona. Gac Sanit 2002;16(5):376-84. http://dx.doi.org/10.1016/S0213-9111(02)71946-8

118. Jansá JM, García de Olalla P. Salud e inmigración: nuevas realidades y nuevos retos. Gac Sanit 2004;18(4):207-213. http://dx.doi. org/10.1157/13062528

119. Instituto Católico Chileno de Migración. Casas de acogida. [consultado 7 febrero 2018]. Disponible en: http://incami.cl/areas-servicios/ casas-de-acogida/

120. Ruz DA. Migrantes: La hospedería de la esperanza. Arzobispado de Santiago. 1 septiembre 2017. [consultado 7 febrero 2018]. Disponible en: http://www.iglesiadesantiago.cl/arzobispado/noticias/otros/migrantes-la-hospederia-de-la-esperanza/2017-08-31/161145.html

121. Comisión Española de Ayuda al Refugiado. CEAR. [consultado 17 abril 2018]. Disponible en: www.cear.es 
122. Ayuntamiento de Madrid. Servicios Sociales. Inmigrantes. [consultado 17 abril 2018]. Disponible en: http://www.madrid.es/portales/ munimadrid/es/Inicio/Servicios-sociales-y-salud/Servicios-sociales/Inmigrantes?vgnextfmt=default\&vgnextoid=04b7ac93081a2510V gnVCM1000000b205a0aRCRD\&vgnextchannel=70e4c8eb248fe410VgnVCM1000000b205a0aRCRD

123. La red de casas del migrante Scalabrini. [consultado 1 febrero 2018]. Disponible en: http://www.migrante.com.mx/

124. Los refugiados y migrantes extra continentales. Experiencia en materia de protección: Nicaragua. Dirección general de migración y extranjería - república de Nicaragua. Septiembre 2010. [consultado 2 febrero 2018]. Disponible en: http://www.acnur.org/t3/fileadmin/ Documentos/nuevo_sitio/2010/CursoDI/ModuloVI_2Nicaragua.pdf?view=1

125. La Iglesia Católica en Bolivia. Obras de la Iglesia. Obra de Movilidad Humana-Casa del Migrante. [consultado 6 febrero 2018]. Disponible en: http://www.iglesia.org.bo/obras-de-la-iglesia/obra/1374-casa-del-migrante.html

126. Tablero HCJ. De Venezuela a Bolivia. Casa del migrante ofrece ayuda a venezolanos. Blog. 29 julio 2017 [consultado 6 febrero 2018 ]. Disponible en: http://devenezuelaabolivia.blogspot.com/2017/07/casa-del-migrante-apoya-venezolanos.html

127. Fundación Atención al Migrante. Arquidiócesis de Bogotá. [consultado 18 abril 2018]. Disponible en: http://famig.arquibogota.org.co/es/

128. Pastoral Social. Cáritas Colombia. Reinauguración del Centro de Atención al Migrante y Refugiado. 1 noviembre de 2017. [consultado 18 abril 2018]. Disponible en: http://caritascolombiana.org/reinauguracion-centro-atencion-migrante-refugiado/

129. El Migrante. Albergue tres Estrellas para extranjeros indocumentados. El Migrante [consultado el 19 de enero del 2017]. Disponible en: http://www.elmigrante.com.ec/articulos/migracion/albergue-tres-estrellas-para-extranjeros-indocumentados

130. Sánchez BC, Oviedo S. Los niños, niñas y adolescentes inmigrantes en Ecuador: avances y deudas en el cumplimiento de sus derechos. Buenos Aires. CLACSO. 2013.

131. Wallace A. ¿Por qué llegan tan pocos niños nicaragüenses indocumentados a EE.UU.? BBC Mundo. Agosto 2014. [consultado 2 febrero 2018]. Disponible en: http://www.bbc.com/mundo/noticias/2014/08/140818_migracion_infantil_centroamerica_eeuu_nicaragua_aw

132. Colectivo IOÉ. Pereda C, Actis W, De Prada MA. Inmigración y vivienda en España. Madrid. Ministerio de Trabajo y Asuntos sociales. 2004 [consultado 5 febrero 2018]. Disponible en: https://www.colectivoioe.org/.../0eaefc67da03a40d6be2755eecf2e5b3c284198b.pdf

133. Ortiz MR, Guerra PV. Caracterización sociodemográfica y económica de las y los emigrantes ecuatorianos. Quito. Instituto Nacional de Estadística y Censos. 2008.

134. Antezana RP (Consultora). Niños, niñas y adolescentes migrantes-América Central y México. San José. Organización Internacional para las Migraciones (OIM), Fondo de Naciones Unidas para la Infancia (UNICEF) y Organización Internacional del Trabajo (OIT). 2013.

135. García Galán R (coordinador), Baraza Cano MP, Cañas García-Otero E, Díaz Gavira C, Domínguez Castellano A, Falces Aramendi A y cols. Manual de atención sanitaria a inmigrantes. Sevilla. Junta de Andalucía. Consejería de Salud. 2007.

136. Programa formativo de la especialidad de Medicina Familiar y Comunitaria. Madrid, 2005. [consultado 5 febrero 2018]. Disponible en: http://www.msc.es/profesionales/formacion/docs/medifamiliar.pdf

137. Finkelstein L. Miradas sobre usuarios migrantes regionales e interculturalidad en salud. En: Novaro G, Diez ML, Martínez LV, del Águila A, Finkelstein L, Tavernelli R. Revista Migraciones Internacionales. Reflexiones desde Argentina. Buenos Aires: Organización Internacional para las migraciones. Argentina. 2017. P. 40-58. 